

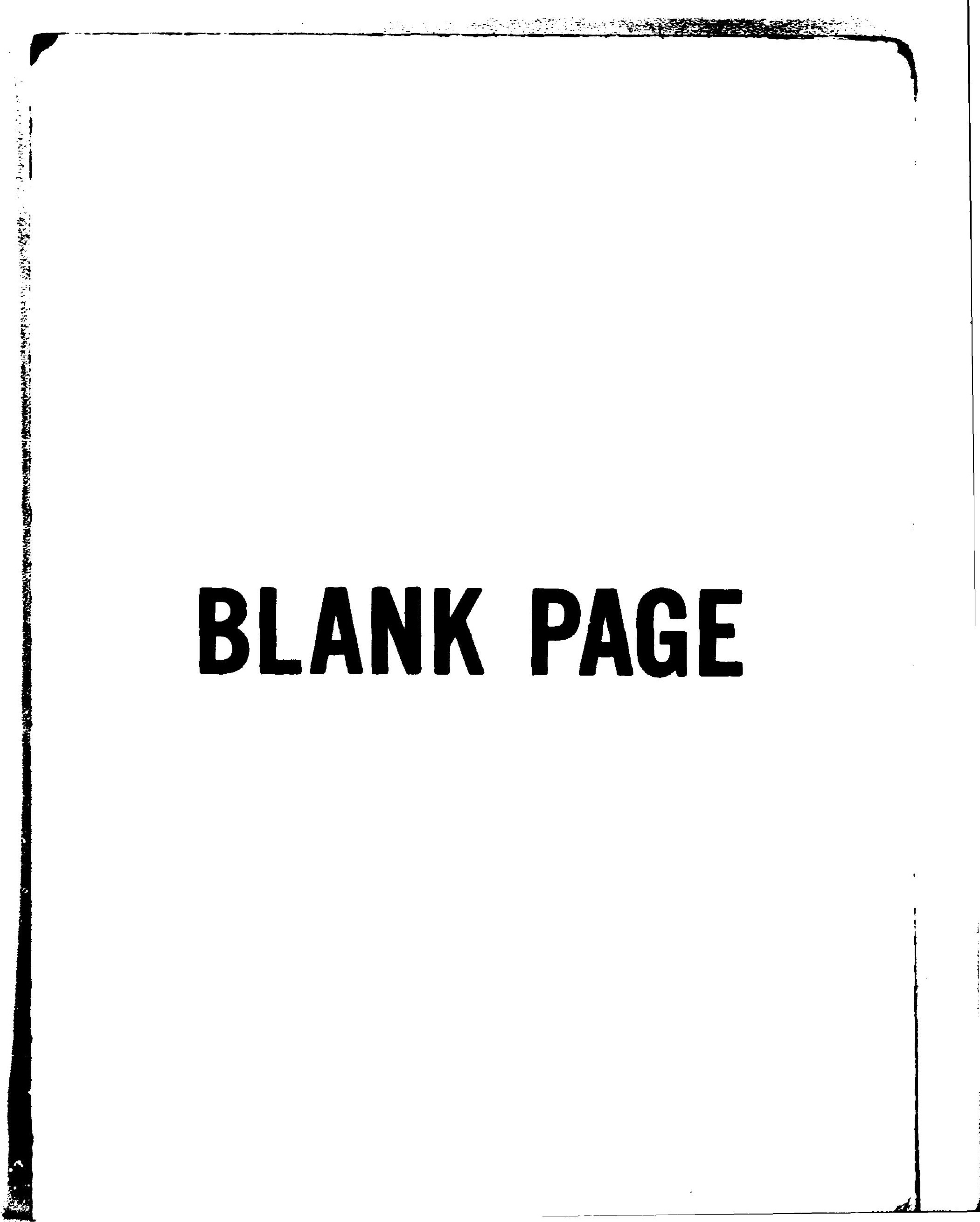


Printed in the United States of America. Available from National Technical Information Service

U.S. Department of Commerce 5285 Port Royal Road. Springfield. Virginia 22161

Price: Printed Copy \$4.00; Microfiche $\$ 3.00$

This report was prepared as an account of work sponsoned by the Iniced States Government. Neither the United States nor the Energy Research and Development Administration'United States Nuclear Regulatory Commission. nor any of then emplopes, nor any of their contractors. subcontractors. Or ther employees. mates eny warranty. express or impled. Or assumes any legal liabiny or responstoulin for the eccuracy. completeness or usefuiness of any intormation. apparatus. product or proceas disclosed, or represents that is use would not infringe priventy owned rights. 
OanLmuREG/ma-103

Disuribution Cougory MRC-3

Contract Ho w-7moseng-25

inetals and cennucs Duvisuon

BNTERM REPORT ON THE CAEEPDONW OF ZIRCALOY FUEL CLADDUUG

D. O. Hobson and C. V. Dodd

Manuscript Completed - Mar. 3, 1977

Dare Published - May 1977

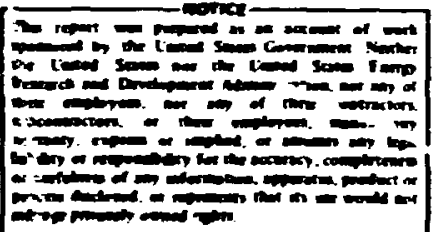

Worice Ths document comains information of a prelimnery neture It is subject to rumsion or correction and therefoce does not represent a final report

Prepered for the

U.S. Nucles Re;ulatory Commistion

Otfice of Nuctor Repelotory Resemch

Under Interagency Agreements ERDA 40-55H-75 and ERDA 40552-75

Prepored by the

OAK RIDGE NATIONAL LABORATORY

Oak Ridge, Tennessee 37830

operated by

UNION CAABIDE CORPORATION

for the

ENERGY RESEARCH AND DEVELOPMFNT ADMINISTRATION 


\section{CONTENTS}

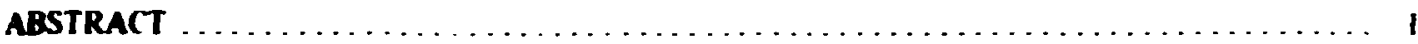

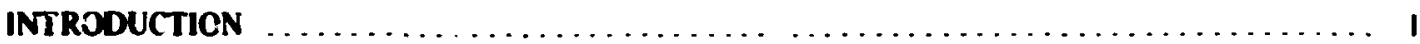

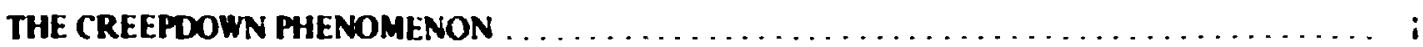

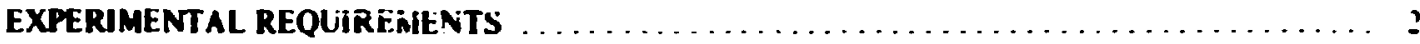

EDDY CURRENT INSTRUMERTATION $\ldots \ldots \ldots \ldots \ldots \ldots \ldots \ldots \ldots \ldots \ldots \ldots \ldots \ldots \ldots \ldots \ldots$

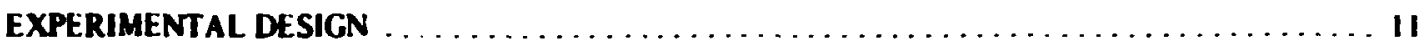

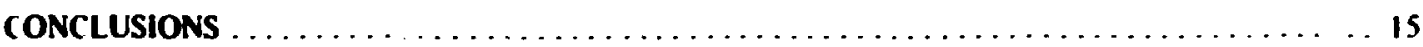

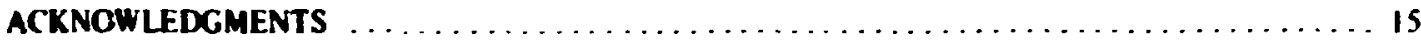

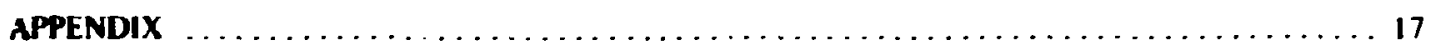




\title{
INTERIM REPORT ON THE CREEPDOWN OF ZIRCALOY FUEL CLADDING
}

\author{
D. O. Hobsin C.V. Dodd
}

\begin{abstract}
ALSTRACT

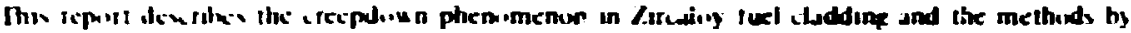

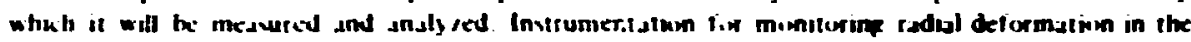

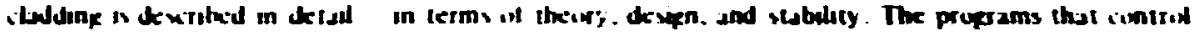

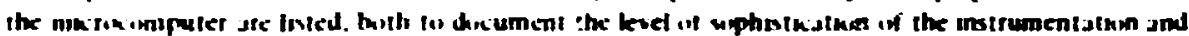
to indic sle the : sibulity al the test eyuipinent.
\end{abstract}

\section{INTRODUCTION}

The creepdown phemunenon. in which Zircaloy fuel claching deforms under the influence of exturt:al pressure and elevated temperalure, is of cuncern to nuckear power reactor designers and operators. Sh h deformation occurs during relatively long periods - thousands of hours of normal and near nursial reacitor operation and results in a gradual closing of the gas gap between the ctadding and the fuel. If a inp should exist between adjactent fuel pellets. it is pussible for the dadding 10 creep down onto the pelkets . nit? then collapse into the gap.

This report desiribes the creepdown pienomenon, the experimental equipment, and the procedure; heing used io study cladding creepdown. including some of the development work necessary in: ine successful functioning of the experimental equipment.

\section{THE CREEPDOWN PHENOMENON}

Creep ir metals is a lime-dependent strain phenomenon that depends upon thermally activated of:.: : movements under an applied stress to achieve specimen deformation. Classically. a uniaxial creep :csa is sharacterized by an initial period during which the specimen strains at a decreasing rate with time (pris.ary sreep). This is followed by a period in which the rate of deformation is relatively constant with time and is it a minimum vaive (secondary creep). Finally, the creep rate begins to accelerate with time and contenues until specimen rupture ocicurs (lertiary creep).

The above scenario generally applies to a uniaxial tensile test. How does one relate this to the rreepdown of a tubular specimen under the influence of external pressure? Two approaches need to be discrusseci at this point: the experimental and the computational. The first approach will be discussed in detail later. The latter approach, as utilized by Pankaskie' and Mohr ${ }^{2}$ for instance, is besed on tike ascumptisn of a creep rate that is a function of effective stress. Temperature and external pressure are considered constant. such a stress is. in turn, a function of the tubing geonietry. Pankaskie assumes a deformation riode in which the tube retains ars oval shape $(\cos 2 \theta \mathrm{form})$ to the point of collapse. Mohr places no such iestriction

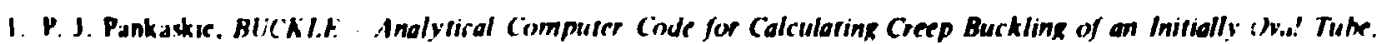
HNWI. 1784 (May 1974).

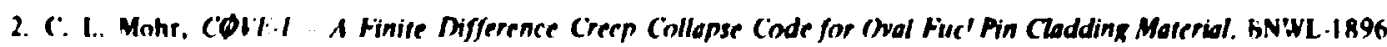
(Wark 1975). 
on the actual shape during deformation. The folluwing diacuasion is based on Mohr's method for evaluating cladding creepdown.

The algorithm used by Mohr in his CQVE-I computer cude involves an incremental solution prociedure in which inelastic changes are cumputed as small changes to the initial elastic stress state. As time or conditions cthange. the inctemental value is computed as a correction to the previous stress state.

The code logic follows this sequence (quoted from ref. 2. to which the equation numbers reier):

1. Read problem input specifications and interpolate material data for the correct temperature.

2. Compute initid elastic deformation and correction for the finite length. The infinite tube calculation is performed using the closed form solution to the differential equation. with the correction for finite length being applied here.

3. Perform detailed elastic stress calculation.

4. Compute effective stress for all nodal points.

5. For the initial time $(l=0)$ print the initial elastic conditions.

6. Compute creep strains for all nodal points based on the effective stress at these points.

7. Uking creep strains, compute bending strain profiles for inplane (MO) and out-nf-plane (Mx) bending. Corrections to the bending stress distributions and creep of the neutral surfaces are also computed. Fquations (27) and (28) ate used for this calculation.

8. Simultaneous solving for the difterential Equations $(17 c)$ and $(19)$ using the Numerov af proximation shown in Equation (20).

9. Correct the computed deflection results for the finite length approximation and combine in Equations (18) and (19b).

10. Compule bending moment corrections to inplane $M \theta$ and out -of plane $M x$ for the finite length.

11. Compute stresses.

12. Compute corrections to the stress states for the inelastic stresses.

13. Compute the rigid body motion or atet clad creepdown.

14. Print results.

15. Examine the collapse criteria; if tube has exceeded its criteria the solution is terminated. If not, 80 on to new time step starting with (3).

The crucial step in this whole sequence is step 6, in which the calculated effecrive stresses at each nodal point are used to calculate the creep strains that take place during a specified time interval. Such a step requires an analytical model for creep behavior in terms of temperature, stress, and any material reaponse characteristics that might be applicable. It is just such information that is unavailable for Zircaloy under the stress state of interest.

\section{EXPERMENTAL REQUIREMENTS}

What experimental studies could supply the information needed to predict cladding creepdown behav. ior? One answer would be to conduct uniaxial or biaxial creep tests that simulate the various stress states to which a tubing specimen might be subjected under extemal pressurization. Creep strain rates, and an 
anajylial mudel derivei trom them. could tinen be used in step 6 of Mohr's program lo calculate cladding strans. Intwitumately. Ihere is a difficulty in this approach that auses sume apprehension that it vill nut work. The number is ereep tests is produce the reyured analytical mudels $v$ ould be very large. In addition. the relolionshsp between those mudels and specimen geometry would renain cunjectura!. That is. a specimen in the proxess of defintusalsun will undergo a serbes of cruss-secitunal shape changes. Faih shape will involve different stress states math through the wall and around the circumference. This causes a certain "thicken equ" situatim: The stress state at any point in the specimen is dependent upon the instantiancuus specimen geumetiy. but the specimen geometry is. in turn. dependest upon preceding stress states. In addition. the specinken tends toward a more and more unstable geometry with time. a geometry that would event wally lead lo sudden cioflapse of a hollow: specimen.

The present experimental program undertakes anuther approast to the problem. Instead of attempting to determine creep rates direilly in the classical sense discussed earlier, the specimen deformation is monitured on the basis of shape changes. This is being achieved by a set of closely spaced radial probes set apainst the specimen sutface. The pusitions of the probes are monitored by eddycurrent tectniques. This results in a record of the radial pusitions of up to 23 points within a $0.050-m$ (2-in. $)$ length on the specimen surface. The data can be recarded at the end of any time interval from approximately 20 sec tc $24 \mathrm{hr}$, so that a bigh density of data an be obtained during periods of rapid deformation and at a slower rate during periuds of slow en steady defurmalion.

Such data provice a reciord of the radial mowements of certain points on the surfac: of the cladding. This raises a question to what extent and how precisely can a surface configuration b: described from a knowledge of the radial movernents of a limited number of points on that surface? The worth of the entire creepdown study depends upon the answet to that question. Cettainly the larger the number of points whrse pusitions are known. the better une is able to describe the surface that contains those points. Also. the simplet the surface configuration, the fewer points are required. The answer to the question can probably be derived from statistical treatment of arailable data. and. indeed. the data are being investigated.

A second question is raised - how does me handle the probe information in order to "know" the shape of the cladding surface? At any given time during a lest, the probes will indicate the position of the surface relative Io the slarting position. Each probe will also have produced a record of its individual movement with time. It will be a simple task to determine the time at which the cladding contacts the "fuel" pellets s.ine of the probes will stop moving. Also. initial rippling of the cladding surface can be detected by undulating values of various probes. The surface shape can be modeled at any particular time by fitting the data from the probes with spline functions or two-dimensional Fourier analysis. How closely such a fit is to the real cladding shape will depend on the simplicity of the shape or on a fortuitous choice of expansion functions and can only be determined by further experimentation.

\section{EDOY-CURRENT INSTRUMENTATION}

Ordinarily, out of reactor tests could have been run in a pressure vessel with a larg inside diameter large enough to accommodate linear variable differential (ransformers (to measure radial strain). Such a system would have allowed the requisite continuous monitoring. but could never have been modified for in-reactor use.

Fddy-current measurement techniques, altheugh quite refined theoretically and in standard use in many areas of experimentation. required extensive development work for use in the present creepdown siudy. Space limitations. especially for the in-reactor study. required an extremely compact deformation. monitoring system. It was decided to concentrate on the eddy curtent radial probe concept and (o) design 
and build an instrument to control and munitur thuse prubes. Following is a desiription of the theory and operation of the eddy-current instrumentation.

Gewert deary. The study utilizes cuits of aluminum ribbon construited by winding that ribbun intu a spiral as shown in Fig. I. A A high-irequency alternating current is passed through the cisil and produces an alternating electrumagnetic field (represented by a vector potentiai 1 ). When the coil is in air. a purely inductive component of the voltage is produced by this inld. and a resistive compunent of the voltage is developed actoss the coil de resistance."

The coil impedance can be calculated from these cumponents. When the coil is brought near a conductor, as shown in Fig. $1 B$, the alternating elec::omagnetic field induces eddy currents in the conductor. which in turn mudily the fireld, ausing the iesistive component of the coil impedance to increase and the reactive component to decrease. With the coil in an impedance bridge, as shown in Fig. 2, a change is produced in the voltage oui $\left(V_{v}\right)$ as the impedance of the test coil varies with respect to the reference coil. The reference coil is alone in air, as shown in Fig. I.A. and the test coil is a distance $I$. from the conductor. as shown in Fig. $1 B$.

Daip of coil. Since the voltage uut of the bridge depends on the coil impedance. we first performed a study to determine the best coil design. Using previously developed design data." and considering the sensitivity of coil-to-disk spacing, change in coil de resistance with cemperature, space limitations, change in resistivity of the disk with temperature. required able length. available electronics, and available construc tion materials, we chose the coil and operating properties shown in Table I.

3. C. V. Didd, W. F. Deeds, and J. W. Luquire. Some fidy-Cument ProMems and Thrir Integred Solurions, ORNL 4384 (April 1969).

4. J. H. Smith and C. V. Dodd, "Optimization of Fddy Current Measurements of Cond lo Cimductur Spaxing." Marter. finel 331 2), 279 (Decomber 1975).

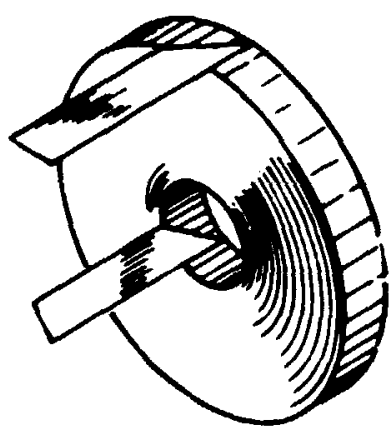

A
OinL-0ing 77-3546

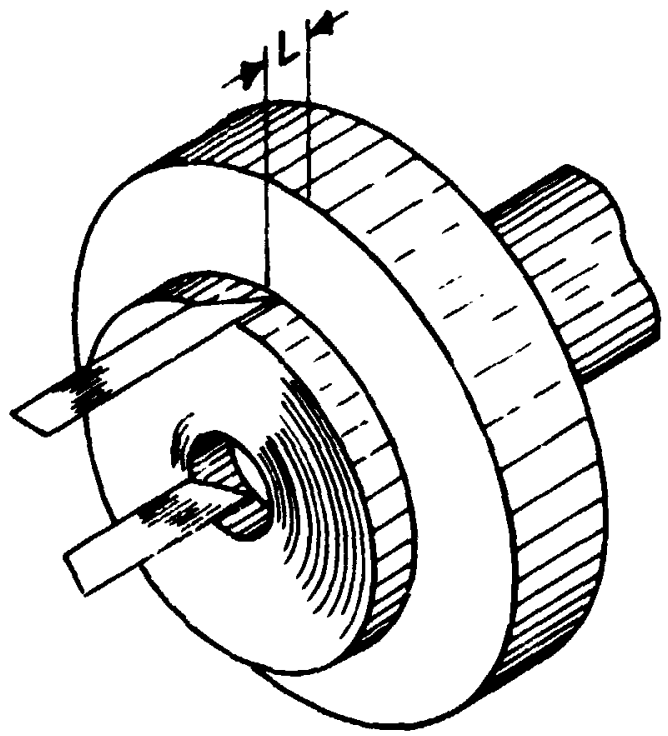

B

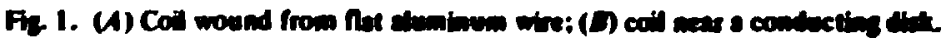




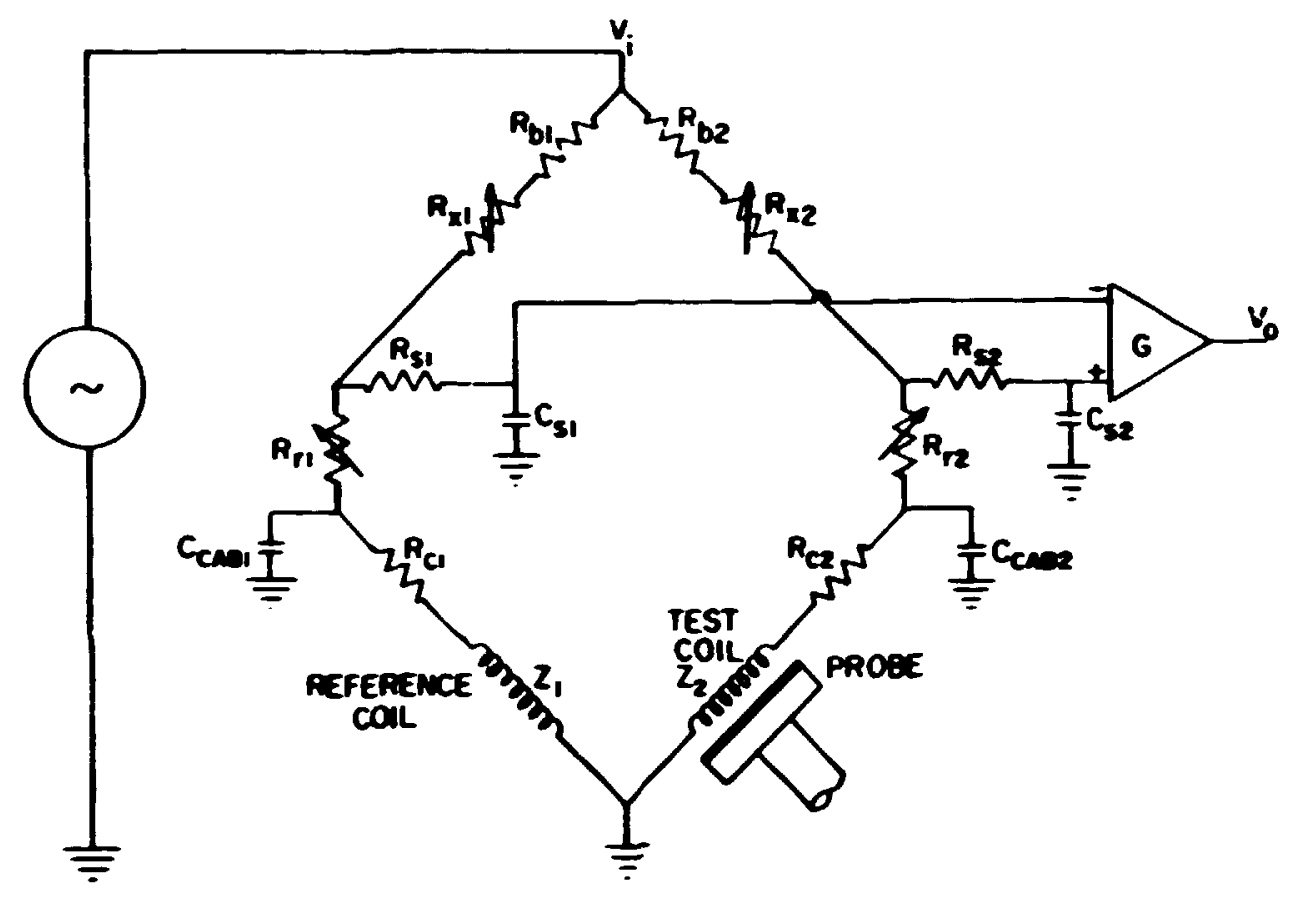

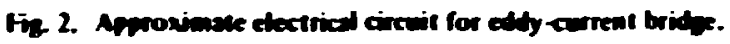

Talke I. Cot and nemation poperties

\begin{tabular}{|c|c|}
\hline$($ ind $(X)$ & $19.213 \mathrm{~m} .111 .1 \mathrm{mos}+1 \mathrm{~m}$ ) \\
\hline (inl II) & 10.1155 in $(10 .(k) 14 \mathrm{ml}$ \\
\hline Cinl kenzilh & 0.0132 in $1(1.07 m 881 \mathrm{mI}$ \\
\hline Cinl Iurns & 24 \\
\hline Meresromxithen & 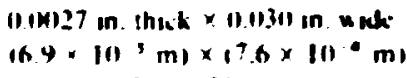 \\
\hline Corlat revistence & 11.1611 s: $25(1,771)$ \\
\hline Cinl indusisnce & I.t4 $\mu \mathrm{H}$ \\
\hline (pperstung frequine: & $2.0 \mathrm{MH}$ \\
\hline
\end{tabular}

High test temperatures precluded the use of lacquet-type insulation on the coil ribbon. Aso. the need to wind the coil turns very tightly suled out the use of glass-type insulation between the turns. The p:oblem wa finally solved by use of thin aluminum ribbon insulated by a thin $\left(\sim 3 \times 10^{-7} \mathrm{~m}\right)$ anodized oxide conting. This allows virtually metal-to-metal contact between the turns. The oxide film is quite adequate for insubting against the $\mathbf{1 5 . V}$ potzntial across the coil.

The impedance was calculated ${ }^{5}$ for this coil at both room temperature and $427^{\circ} \mathrm{C}\left(800^{\circ} \mathrm{F}\right)$. with various spacing (lift -1)ffs) between the coil and a $0.25-\mathrm{mm}(0.010$-in.) corpper coating on a stainless steel disk.

A plot of these results is shown in fig. 3. The impedances have been normalized by dividing both components by the magnifude of the reactance of the coil in air $(\omega / .0)$.

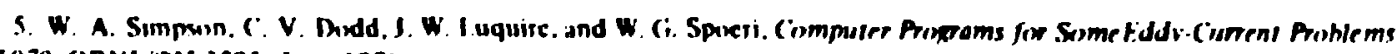
1971). ORNI./TM-3295 UUne 197I). 
OPMn-DWG 77-3544

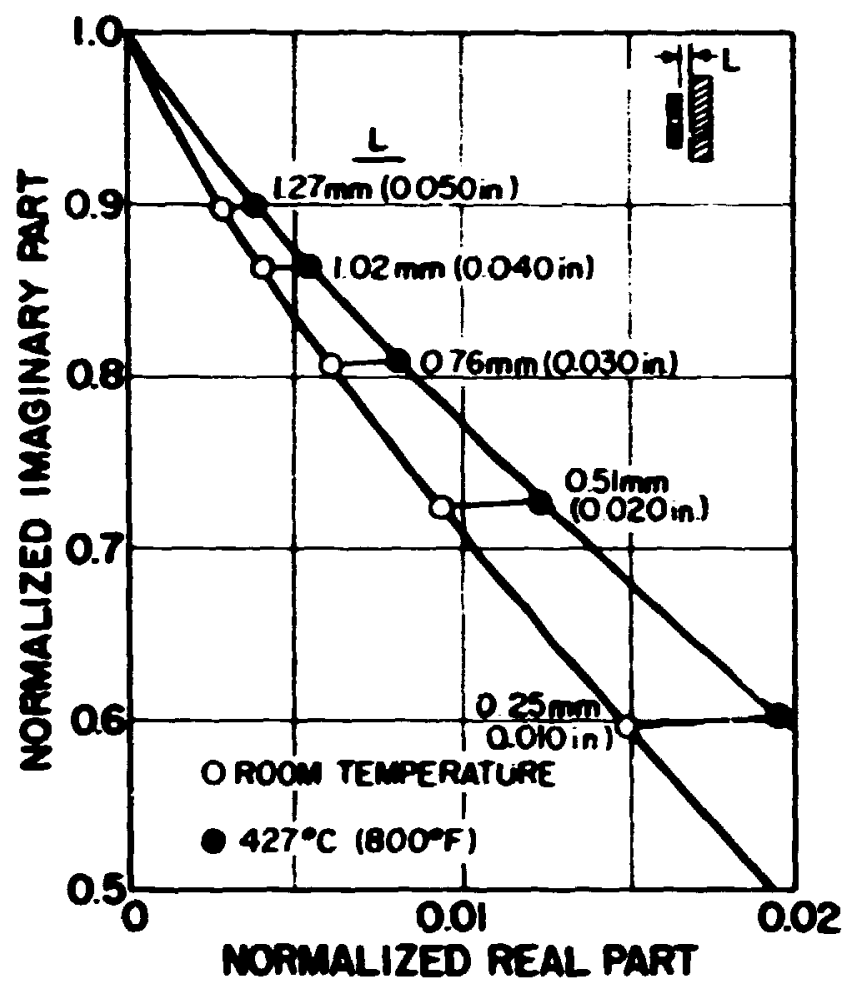

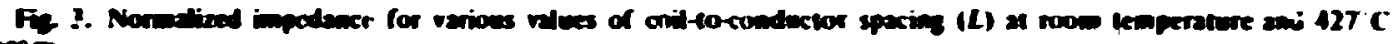
(80) $\mathrm{F})$

The impedance change is a nonlinear function of the spacing change. and th:re is very little change in The magitude of the coil impedance as the temperalure varies from $21^{\circ} 10427^{\circ} \mathrm{C}\left(70^{\circ}\right.$ to $800^{\circ} \mathrm{F}$ ).

Aatys: of bidte cicuit. These impedance values are put into the b: iuge circuit, and the voltages for the various values of the bridge parameters can be calculated. The voltage out of the bridge circuit in Fig. 2. is given by

$$
\begin{aligned}
V_{o}=V_{i} G\left[Z _ { p 2 } \left(R_{b)}\right.\right. & \left.\left.+R_{x 1}+Z_{p 1} \times 1+j \omega C_{s 1} R_{s 1}\right) \quad Z_{p 1}\left(R_{b 2}+R_{x 2}+Z_{p 2} \times 1+j \omega C_{s 2} R_{s 2}\right)\right] \\
& \div\left[\left(R_{b 1}+R_{x 1}+Z_{p 1}\right)\left(R_{h 2}+R_{x 2}+Z_{p 2} \times 1+j \omega C_{s 1} R_{s 1} \times\left(1+j \omega C_{s 2} R_{s 2}\right)\right]\right.
\end{aligned}
$$

where

$Z_{p 1}=$

$\frac{\left(1+j \omega C_{s 1} R_{s 1}\right)\left\{R_{R 1}\left[1+j \omega C_{C A B 1}\left(R_{C 1}+Z_{1}\right)\right]+R_{C 1}+Z_{1}\right\}}{\left(1+j \omega C_{s 1} R_{s 1}\right)\left[1+j \omega C_{C A B 1}\left(R_{c 1}+Z_{1}\right)\right]+j \omega C_{s 1}\left\{R_{R 1}+\left[1+j \omega C_{C A B 1}\left(R_{C 1}+Z_{1}\right)\right]+R_{C 1}+Z_{1}\right\}} \cdot$ 


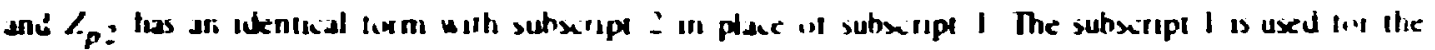

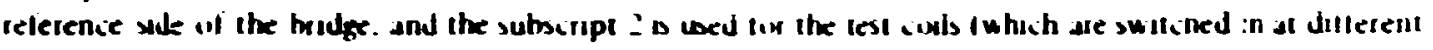

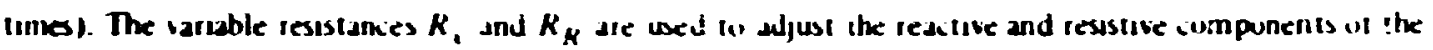
budge respectively. The resistance $K_{1}$, is the able and cini resistance. and this varies win temperature

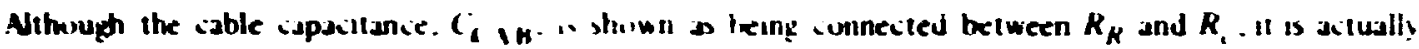

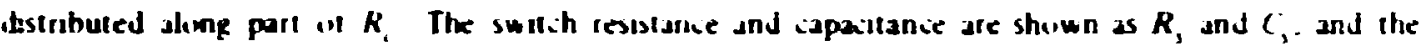
diterential amplitier pan is $G$. While thus atcuit is a smplitied app:cusmation of the aitual ariul'. 1 : is at very gund approxumation and repaesents the magur efteits. The numinal values of the bridgr parameters are gven in Table : Whik must "ft the bridge cimponents ate quite slable, some of them do vaty and auxe errors in the mexurements.

The errurs in the coil-torionduitor spaing measurement dice to drifts in the cilcuit are summariced un Table 3. Since the impedence change is a nonlinear function of the culfoionduitur spacing. the amount of error in sume instamies will thange with the amount of spaing. The makx eriors are due to the variatiun in other cumponents of the system. namely. In the cupper resustivity $(1.732$ (o $3.03 \mu .2-\mathrm{m})$ and the di resustance change 12.7 to 3.0 \$ 3 as the assembiy is heated. Also. a change in the cable capacilance that is not balanied by a simiar thange in the wher kg of the bridge can ause a large error. The operating frequency is about one-tenth the resunant frequency and will have to be reduced if the capacitance is increased by any large amount. In genetal. huwever. the errors are yute small. The inpul voltage. $t_{\text {in }}$ is also used for the reference voltage. su variations in thus voltage produce no errors. There is a digtizing error

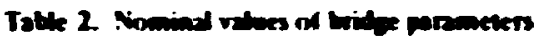

\begin{tabular}{|c|c|c|}
\hline Parsmeter & Villuk & 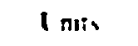 \\
\hline i, & 111 & Vinturen \\
\hline$R_{b 1}^{\prime} \cdot R_{b 2}$ & 1511 & (Mmms \\
\hline$R_{\times 1} \cdot R_{\times 2}$ & 11511 & ( $\mathrm{hm}$ \\
\hline$R_{31} \cdot R_{32}$ & 65 & nhms \\
\hline$c_{31}^{31} c_{32}^{32}$ & $\ln (x)$ & Mintar ads \\
\hline$R_{R 1} \cdot R_{R 2}$ & 115 & $(\mathrm{~mm}$ \\
\hline$R_{11} \cdot R_{2-2}$ & 3 & Mhms \\
\hline cанicloнz & 8311 & Pherits \\
\hline ii & 15 & \\
\hline$r_{1}$ & $11+11^{\circ}$ & Inm, \\
\hline & $115+115$ & $1 \mathrm{~mm}$. \\
\hline liequen; & $\therefore 111^{\circ}$ & Herty \\
\hline
\end{tabular}

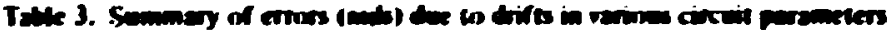

\begin{tabular}{|c|c|c|c|c|c|c|c|}
\hline $\begin{array}{l}\text { Pal am-ter varied } \\
\text { Niminal value } \\
\text { New value }\end{array}$ & 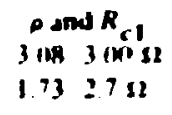 & 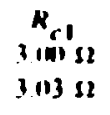 & $\begin{array}{l}R_{11} \\
6511 \\
651\end{array}$ & $\begin{array}{l}\text { Col } \\
\text { limipi } \\
\text { IIIpl }\end{array}$ & $\begin{array}{l}\text { canis } \\
\text { sinel } \\
\text { 838 pl }\end{array}$ & 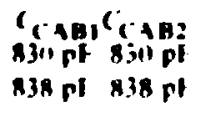 & $\begin{array}{c}\text { I } D \\
\text { Dyeitiong } \\
\text { eitur }\end{array}$ \\
\hline \multirow{5}{*}{ 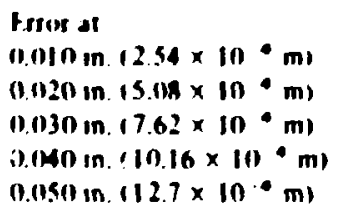 } & तथा & $\cdot 11.14$ & (1) PXW & +111 & 113 & $n(m)^{-}$ & $=(1) \ln ) 8$ \\
\hline & 191 & +1114 & +llinus & +1111 & ด I A & "Ins & ? \\
\hline & $\| 91$ & +11.15 & $+11 \mathrm{mms}$ & +1112 & 11200 & "II: & 6111110 \\
\hline & $(1,91)$ & +1105 & I & +11111 & $\therefore: 265$ & NIIn & -n11:: \\
\hline & n 91 & +10.15 & -110114 & - H) & $(1+4)$ & 0.118 & $=11113,11$ \\
\hline
\end{tabular}


II the anakg-lo-diglal comverter which will also produce a simall error. as shown in Tishle 3 . The voltage icahng can be cinverted lo lifi-ofi values lo within $\pm 3.81 \times 10^{-} \mathrm{m} 10.00015 \mathrm{in}$.). using a simple

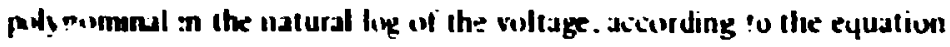

spating $\left.=C_{10}+C_{1} \ln 1+C_{2} \ln 1\right)^{2}$

This eyuation is ielermined during the calibration privess firr each coil.

Niv that we have disiussed the design ot tile bridge circuit for making the measurements. we will inusus the overall instrumentation used.

Comper systere to messure spacing for an army of coils. Since we need to measure the spacing for an arras of coik. we designed a computer-controlled instrument, shown in Fig. 4. to perform the measurements. linearixe the results. compute the changes in dimensions. and stop the test when the changes reach a preset levet. The power amplifier is used to generate a 10-V (peak to peak) signal. which is applied through + resustance to all It civils. Each resistor and coil forms one side of the bridge shown in Fig. 2. and the reference coul forms the orher side. Mie hridge is furmed when the signal from one of the 2I test coils is swicted into the differential amplifier to be compared with the signal from the reference coil (which remans swilcted (m). The difference signai is ampintict. and its magnitude is converted to dc. This analog volta is coaverted to a digital signal wi:h a 13-oit. analog-to-digital converter. The digital signal is fed into a macrompaner, where the signal is processed it, va. wous ways and then sent to both serial and parallel data

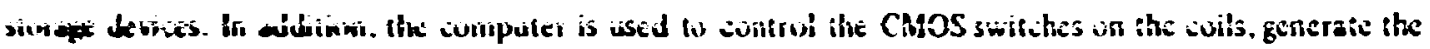
tumane sigats tix the analog-to-digital converter, and respond to the various front panel switches and a preser stixik. The inictociomputer. an NDT-COMP8, was developed tor general eddy-current tests and is susered in a separate repolt..$^{6}$ The microcomputer is used to control both the actual tests and the calibrainm and ce? up of thrse tests.

Onariven of the microcompoter-controlled creepdown instrument. The creepdown instrument is uperaled th the cintruls shown in the upper left-hand corner of Fig. 5. When the RESET push buttun is activated, it resets the computer and plits all of the input-output lines in the high-impedance state. The computer will respond to bta from a terminal device in this state through the NDT-COMP8 monitor progams. The START button initiates the execution of the main control program. The terminal is then used as an outpul-only device.

The STROBE bution will cause data to be printed on both the terminal and the thermal printer :if they are in lones. If the system is in the RUN mode. a STROBE signal will cause all 23 channels to be read and panied out. This signal is obtaine! from either the front panel push button or the preset clock. The clock wh then reset i:xeli and start the timing cycle again.

If there is no strobe signal. the computer will SC AN all 23 channels. making a single reading of each channel. If the MILS switch is on and the lift-off has been zeroed at least once, the value of lift-off of each channel will be compared with preset maxima and minima and halt execution (STOP) if these limits are exieeded. If a STOP vicurs, all 23 channels will be printed out, the clock halied, and then the computer slops the progam.

If \& STROBE signal is received when both the MILS switch and the SET ZERO switch are on, the litt-itt and the count number will be rerced. If the A/D OUTPUT switch is on, the raw analog-to-digital inverter readings will be printed oul.

6 I I indd and (;. D ( onnell. The WDT COMP8 B/hrocompurer. ORNL/TM-5773 (March 1977). 


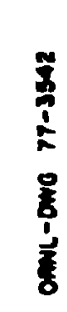
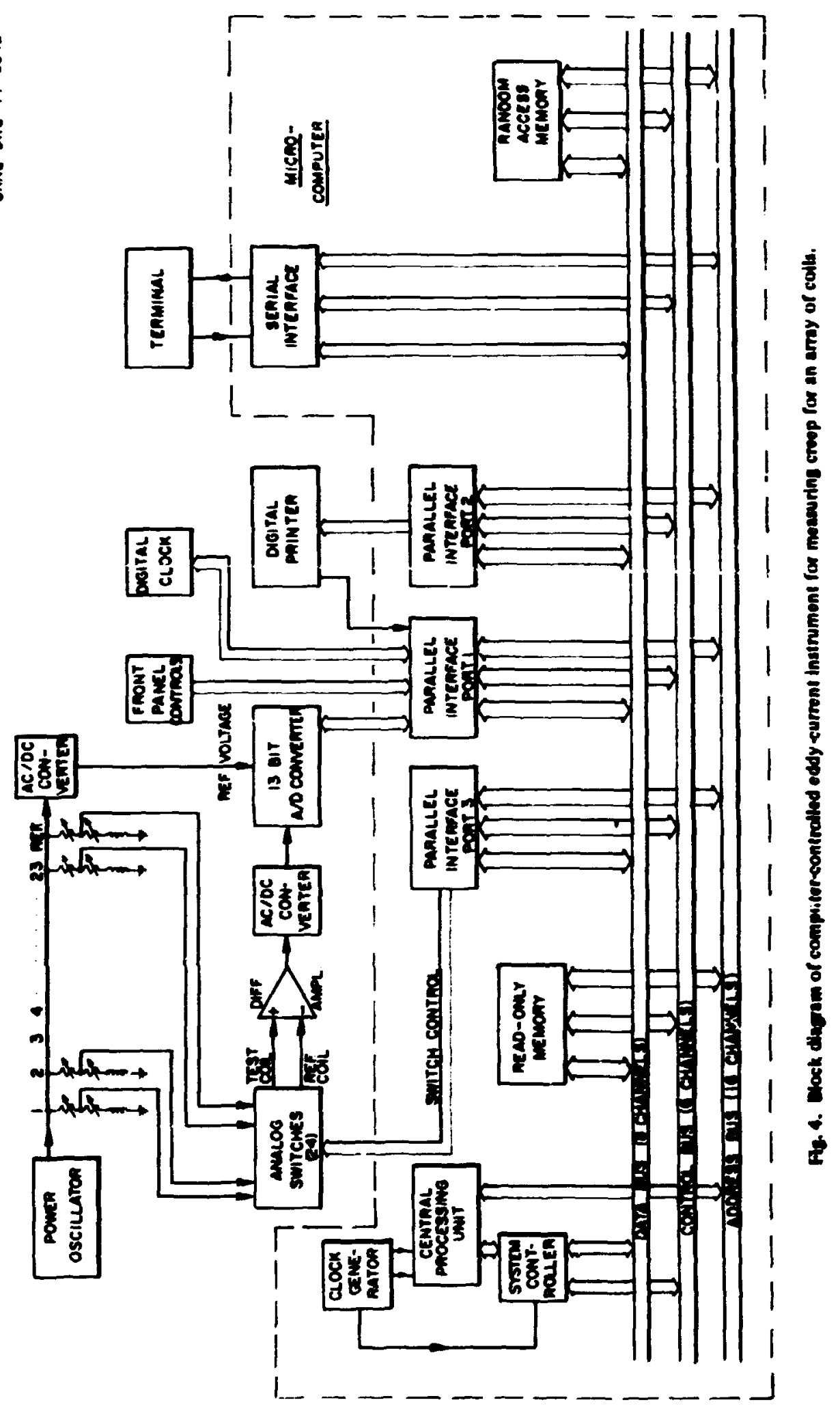
One-0us n-354

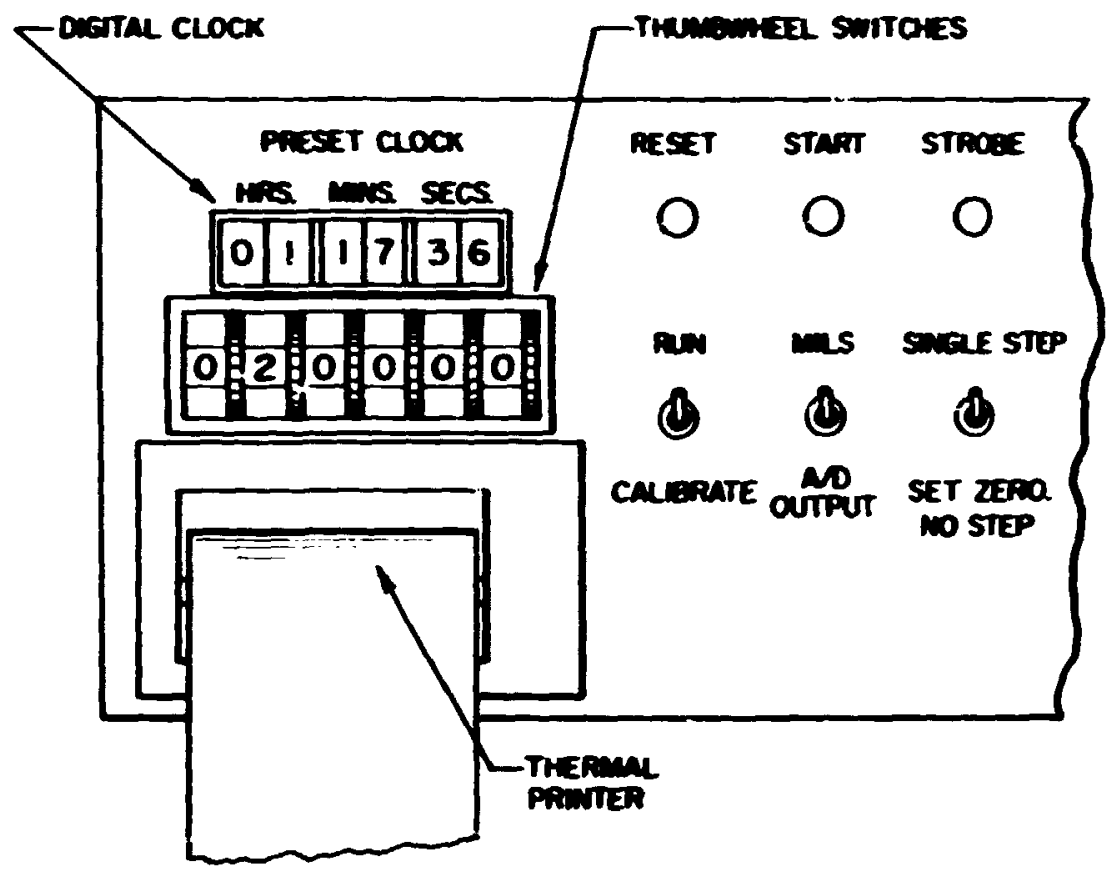

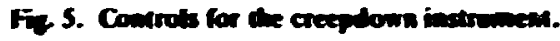

If the system is in the CALBRATE mode. a STROBE signal will cause either 23 or 24 channets to be read, and the last one will be printed out. The clock will not be reset. If the SINGLE STEP switch is on, the channel printed out will be one greater than the previous one. If the NO STEP switch is on, the same channel that printed out the last time will print out again. If the 23rd channel was printed out the last lime. SINGLE STEP will cause the first channel to print out with the next STROBE signal. The value will be printed in mils with the MILS switch on, or the raw analog-to-digital converter value will be given with the AD OUTPUT switch on.

In the RUN mode, the count number will be printed at the start of each set of readings and a line feed will operate at the end. The channel number of the reading is alsc printed to the left of each reading. The terminal will print nut the exponent of the reading if it is not zero, but the thermal printer ignores the exponent.

When the RUN switch is on, each reading printed out is the average of eight analog-to-digital converter readings. In the CALIBRA TE mode, however, only the result of a single reading is printed. Any value of time between 10 sec and 24 hr can be preset into the clock switcties, although the readings and printing lake about $25 \mathrm{sec}$ (with a 300 -baud printer).

Now !iast we have seen how the instrument operates, we will discuss the computer programs used.

Computes programs for the creepdown cest. The instrument uses both read-only memory (ROM) and read-write memory (RAM) for its operation. The ROM is used for program storage, the RAM is used for storage of intermediate results, and both are organized in IK (1024) by eight: segments as shown in Fig. 6 . There are three of these segments used for ROM and one for RAM. 


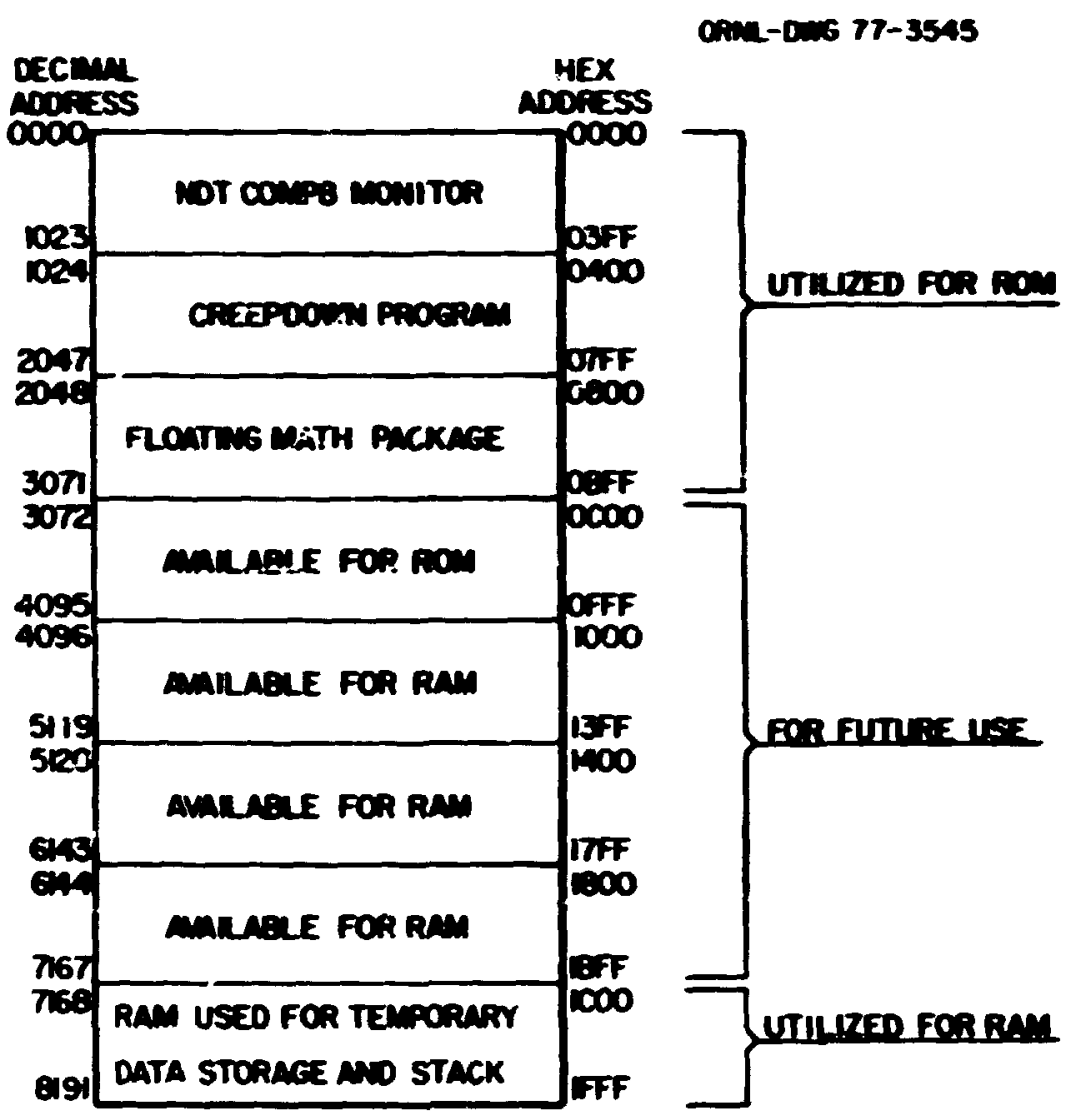

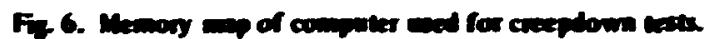

The addresses in Fig. 6 are given in both decimal and hexadecimal (base 16). For the remainder of this section, only hex addressee will be ueed. Only the first three ROM and the last RAM sections -ctually have memory chips pluged into them (the sockets are blank in the others). The discussion of the NDT-COMP8 and the foating-poini math package are given in ref. 4 and will not be repeated here. A list and summary of the programs in the memory for the control of the creepdown test are given in Table 4 . All of these programs are contained in a single PROM (programmeble read-only memory) chip. which is pluzged into the address starting at $\mathbf{4 0 0}$ (hex).

In addition to the program storage in ROM, there are 3 bytes $\times 23$ channels stored for the $C_{21}$ constants (from 45B to 49C) and 3 bytes $\times 23$ channels stored for the $C_{\text {! }}$ cunstant (from $4 A 0$ to 4DS). In both cases the first byte is the exponent, the second byte the high part, and the third byte the low part of the mantisa. The RAM storage used is summarizad in Table 5. A listing of the individual programs is given in the Appendix.

\section{EXTERIMENTAL DESHGN}

The original design for the eddy-current coil probe array, which consisted of four sets of axially distributed probes, was lested in iwo creepdown experiments. The design was found unsatisfactory because of difficulties in calibration due to the lack of individual coil adjustment capabilities. We have redesigned 


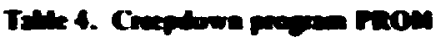

\begin{tabular}{|c|c|c|c|}
\hline Nunor & athes & 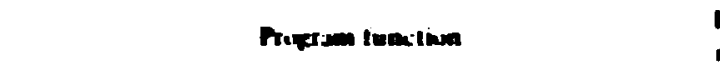 & $\begin{array}{l}\text { Meviruss } \\
\text { reziners }\end{array}$ \\
\hline Setup & (M⿻上) & 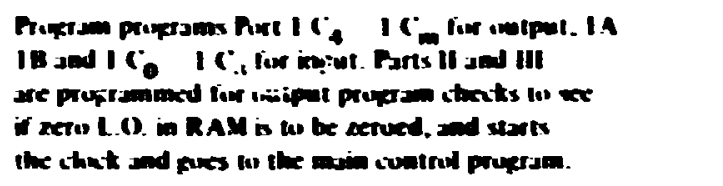 & ABCHEI \\
\hline MAKT & 0438 & 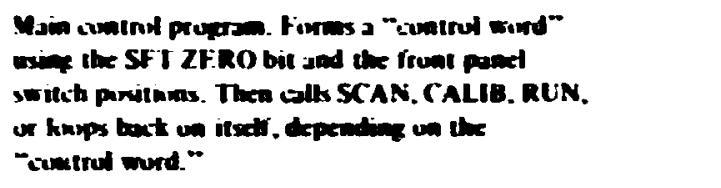 & ABCDEHLE \\
\hline AV(IDT & 0531 & 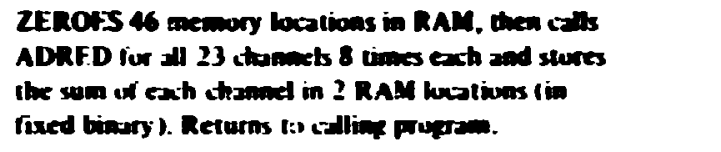 & A BCDE:HLI \\
\hline CEKST & $\cos 0$ & 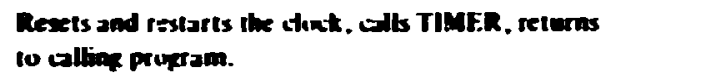 & $A B$ \\
\hline SHTLO & OS9A & 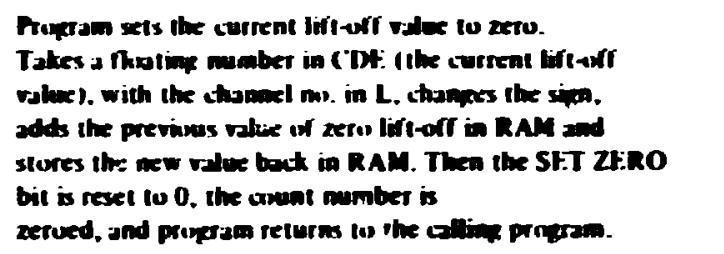 & A BCDEHL \\
\hline LINAR & 0538 & 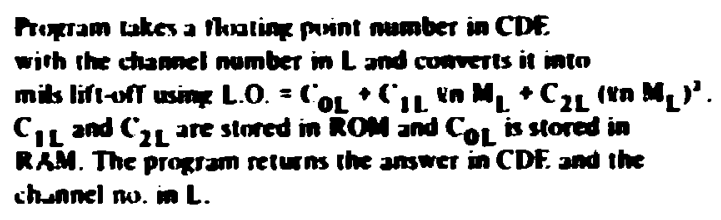 & A BCDEF \\
\hline STOP & 0621 & 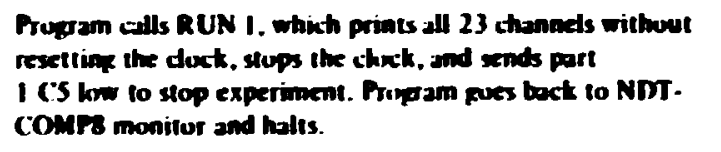 & A BCDEHL \\
\hline E:STST & $062 B$ & 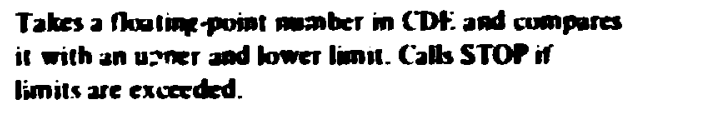 & A BCDEHL \\
\hline SCAN & OSt5 & 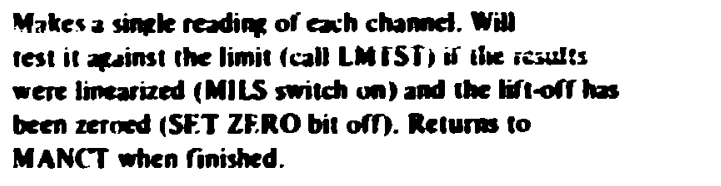 & A BCDFHL \\
\hline TIMFR & OG6D & $\begin{array}{l}\text { Gives a delay of abuvt i msec when colled. Returms } \\
\text { to calline program. }\end{array}$ & A BCF \\
\hline
\end{tabular}

Resets the clexk, increments, and prints the count number. Calls A VGDT. Linearizes the data if MILS switch on, sets zero L.O. if MILS and SFT ZFiRO switches un. prints out dala in indicated form. Returns to calling program.

DATRD if MILS switch is on. and returns with nooting number in CDE. 


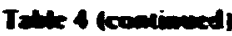

\begin{tabular}{|c|c|c|c|}
\hline Vim & Adutrex & Promstm tunithn & $\begin{array}{l}\text { Destruys } \\
\text { nematers }\end{array}$ \\
\hline CALB & InsI I & 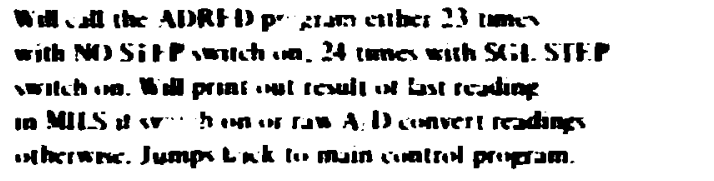 & A $H C^{-} D E \| L 1$ \\
\hline Almfin & $: 1712$ & 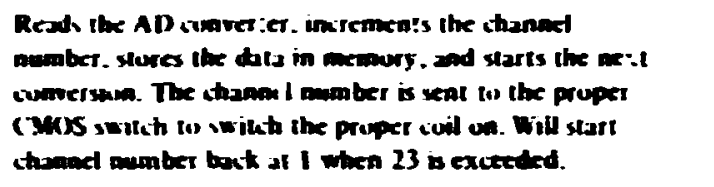 & A BCDEHLF \\
\hline XXIL & 0701 & 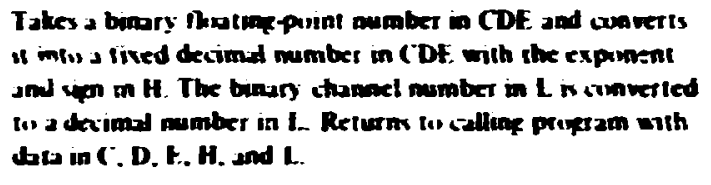 & ABCDEHLI \\
\hline TYMTR & 1791 & 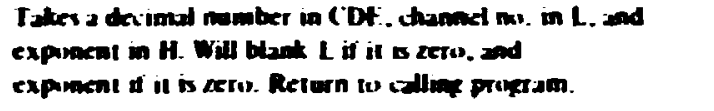 & $\boldsymbol{A}$ \\
\hline THMR & D7F 3 & 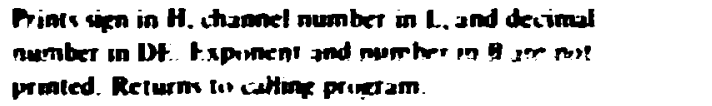 & $\lambda$ \\
\hline
\end{tabular}

Tane 5. Sumary of RAM sarese

\begin{tabular}{|c|c|}
\hline Adtress & lised to sture \\
\hline 1000 & The ratue of the IC N)RT (tissm the frunt manel switiches) \\
\hline $1001-1002$ & The ciont number (the number of "R(iN" readings made) \\
\hline 10031004 & (Theik number, to see if zern I.O. shinold be set to nefo \\
\hline ICOS IODS & In $M_{i}$ \\
\hline $\mathbf{1 6 0}$ & Set zeru lift-off stutus word 110000000 if nut set, IMKO) 0000 if set \\
\hline ICIO ICI: & lsed by hooting point muth paikape \\
\hline 1020 & Chas (charinet number) \\
\hline 16221652 & AD comverter bla 12 bytes each for 24 channels) \\
\hline $165310 \%$ & 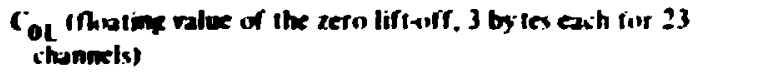 \\
\hline $\begin{array}{l}\text { ICA2 ICFF } \\
\text { IFDO IFFI }\end{array}$ & $\begin{array}{l}\text { Avetafe vilues for } 23 \text { channels. } 2 \text { by tes pet channel } \\
\text { Reterved for stack }\end{array}$ \\
\hline
\end{tabular}

the system to prowide a double-helical arrangement of coils mounted in a cylindrical aluminum block that surrounds the specimen tube. The probe irientation is shown in Fig. 7. The probes extend over a $50.8 \mathrm{-mm}$ (2-in.) length and are spaced $6.35 \mathrm{~mm}(10.25 \mathrm{in}$.) apart. Each coil is individually adjusiable in the radial direction and can be balanced and catibrated in situ by means of special mandrels inserted into the aluminum cylinder. The coil and probe urangemenl within the cylinder is shown in Fig. 8 .

The double helix configuration. positioned within the aluminum cylinder. is also going to be used in the in-reactos tests in the Netherlands. Our present we will give experience with the test configuration before the in-reactor tests start. 


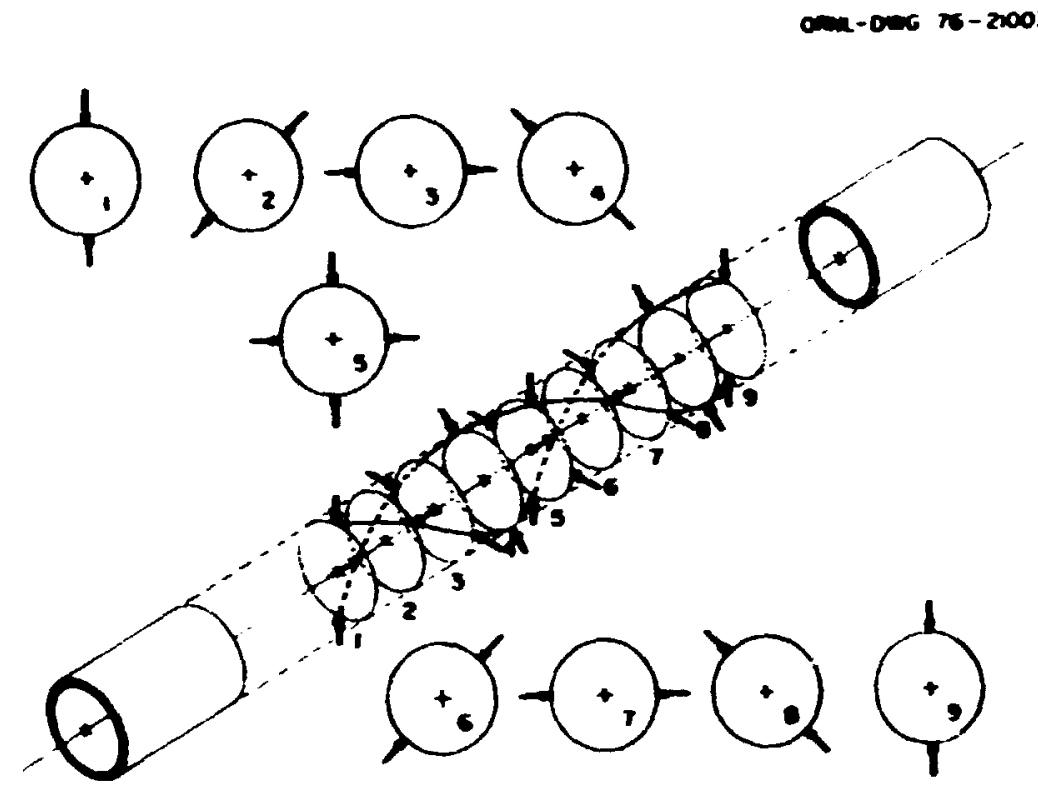

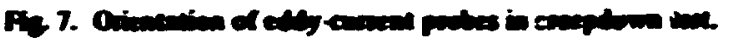

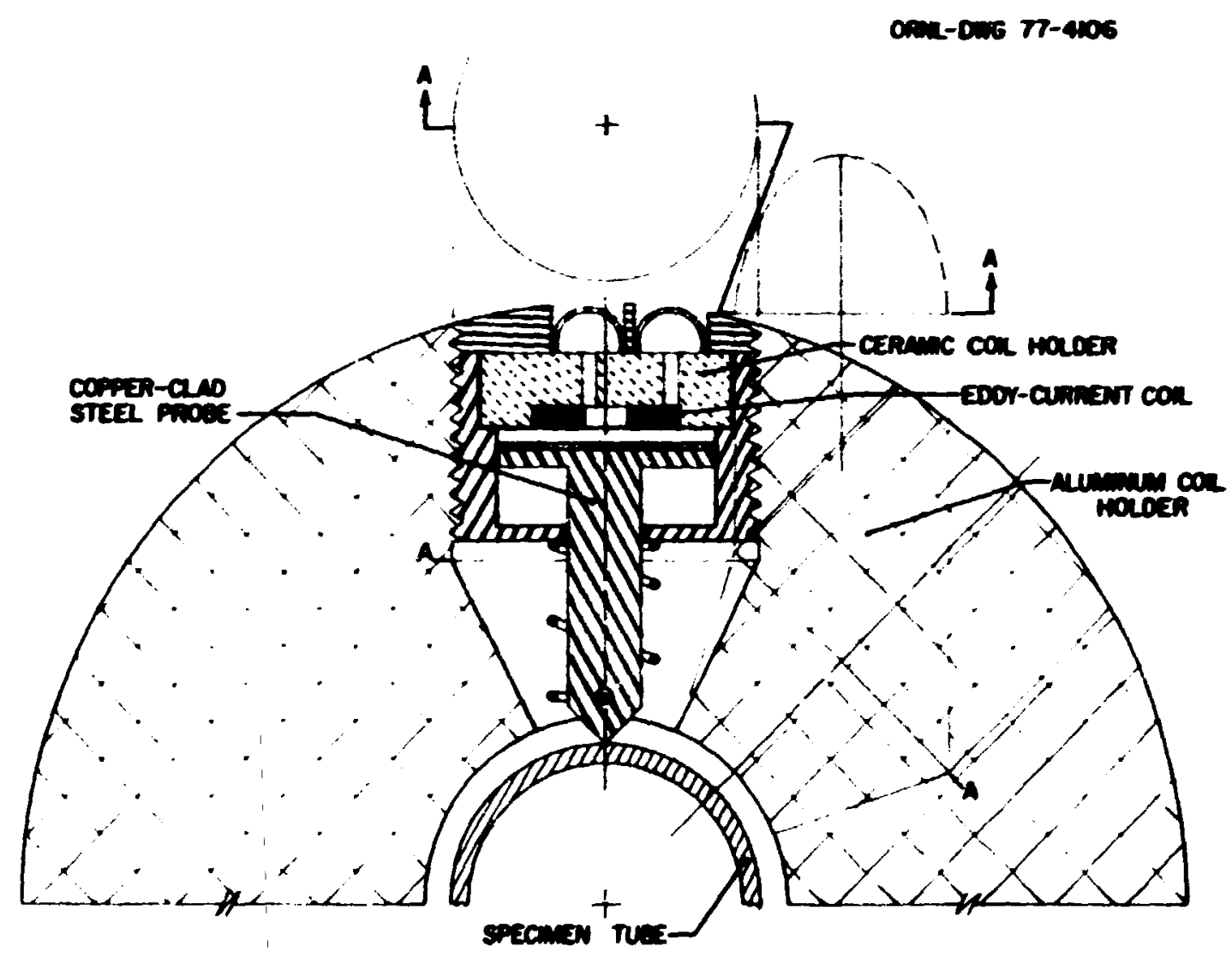

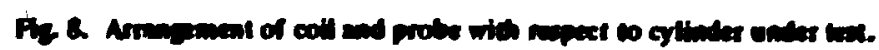




\section{concuusions}

This repurt discusses the mecthanics of the creepduwn process a applied to Ziecaloy fuel cladding. Particular emphasis is given to the differences between the test methods necessary for the study of dadding creeptown due to external pressure and the methods used to study more conventional stress states.

The equipment described herein and the experimentation in which that equipment will be uaed have been desipned and developed for this study. The problems addressed are technically complex and experimentally difficult, a shown by the fact that there is no information axibable on the continuous creep behavior of a fuel dadding tube subjected to external pressurization. The apparatus described in this report is capable of providing such information and. in addition. is capable of providing it in an in-reactor environment.

\section{ACKNOWLEDGMENTS}

The authurs wish to thank T. D. Owing and L. D. Chitwood for their support in the design and construction of the equipment used in this study. Thanks are atso extended to W. E. Deeds and K. C. Liu for reviewing the manuscript and to Technical Publications for preparing the document for reproduction. 
NHENOLX

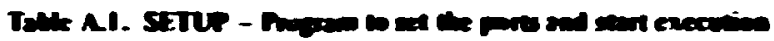

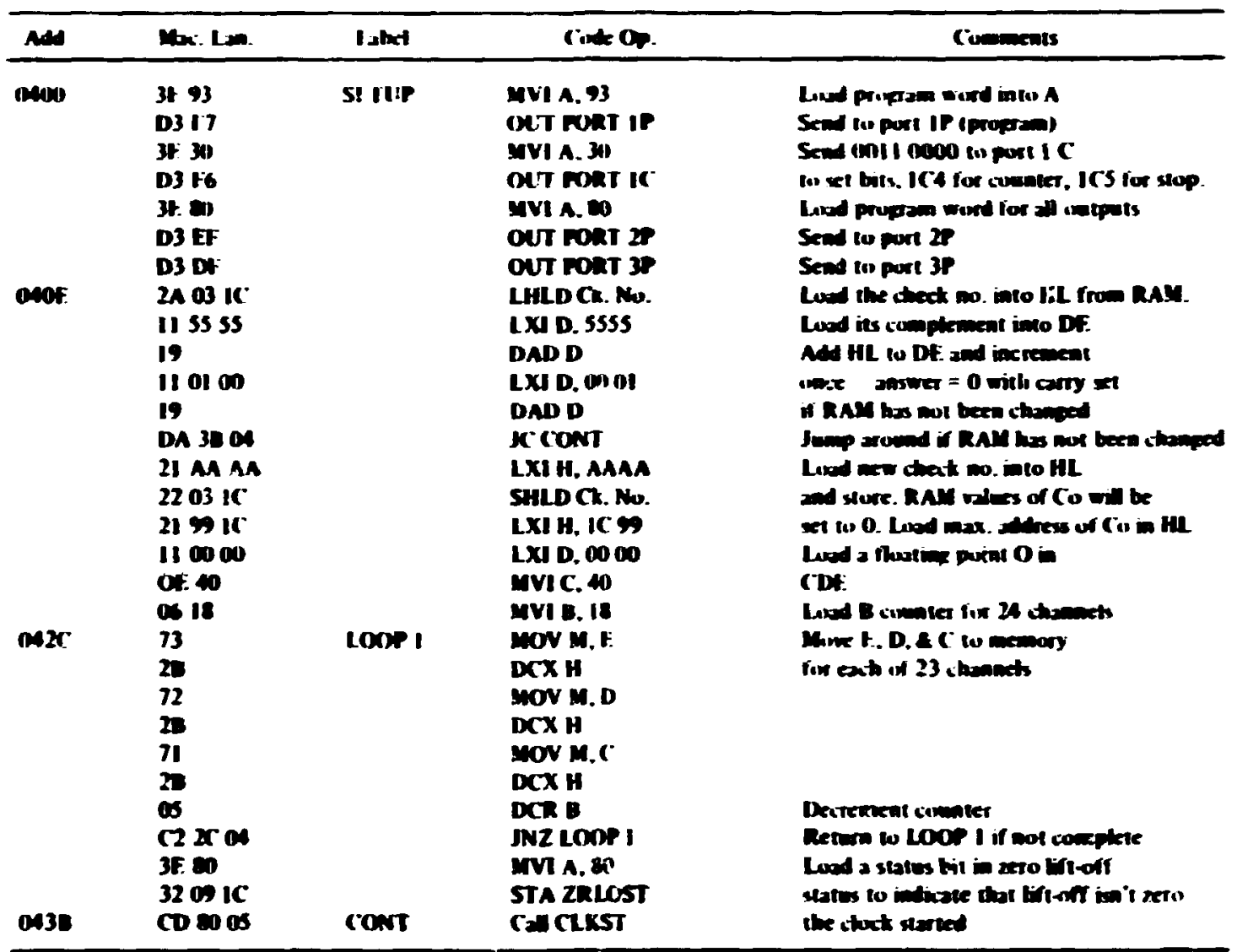

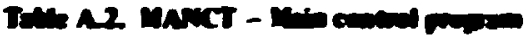

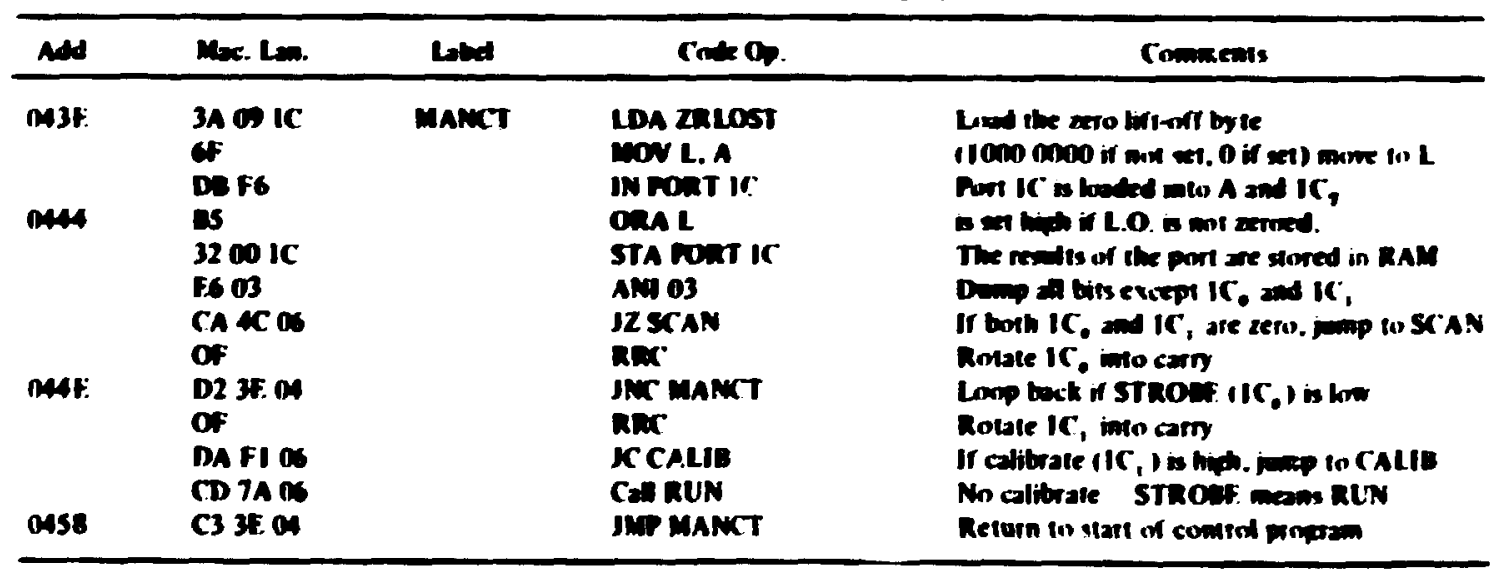




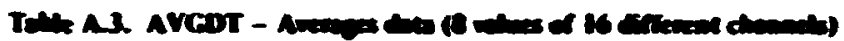

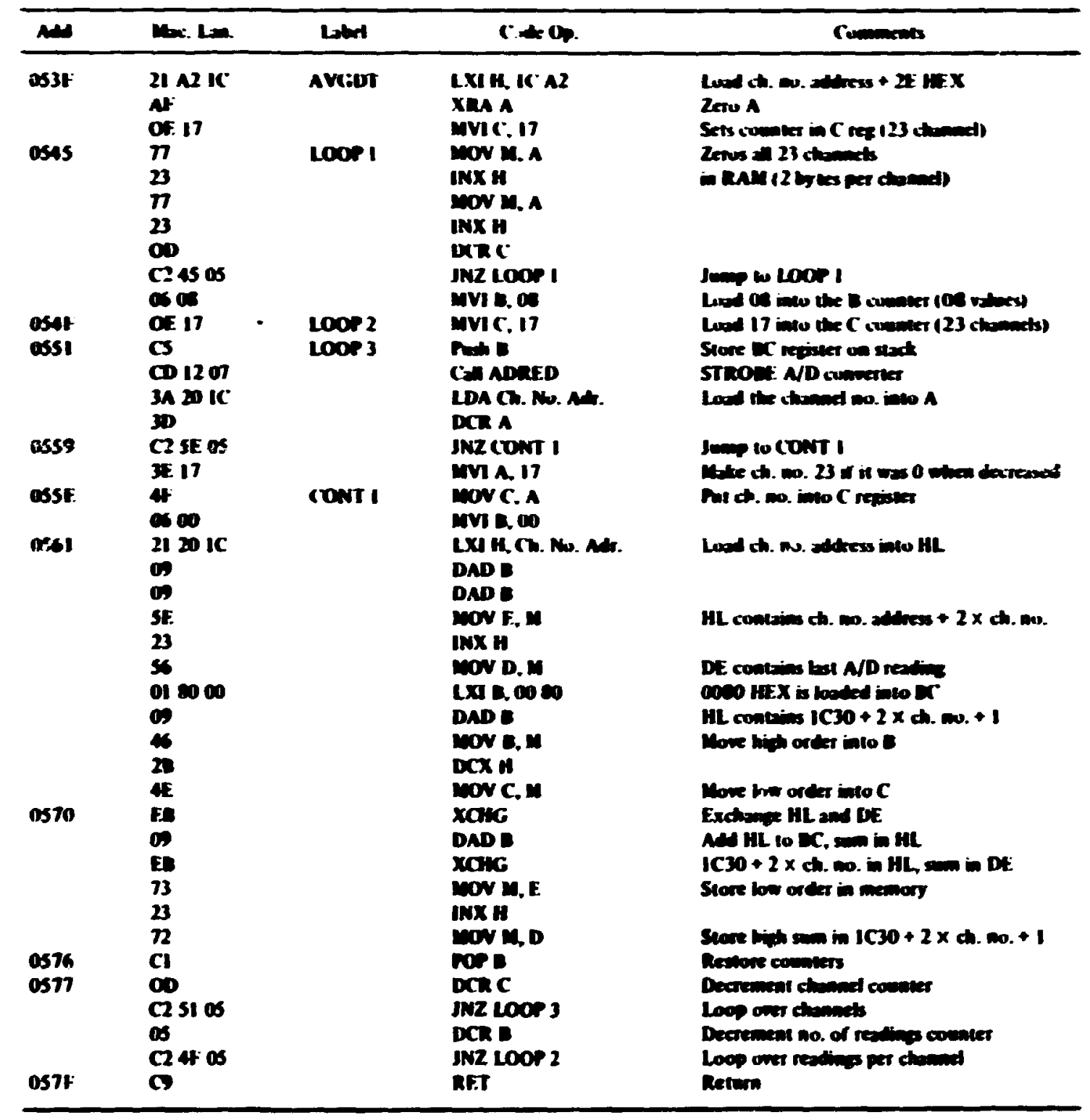




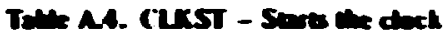

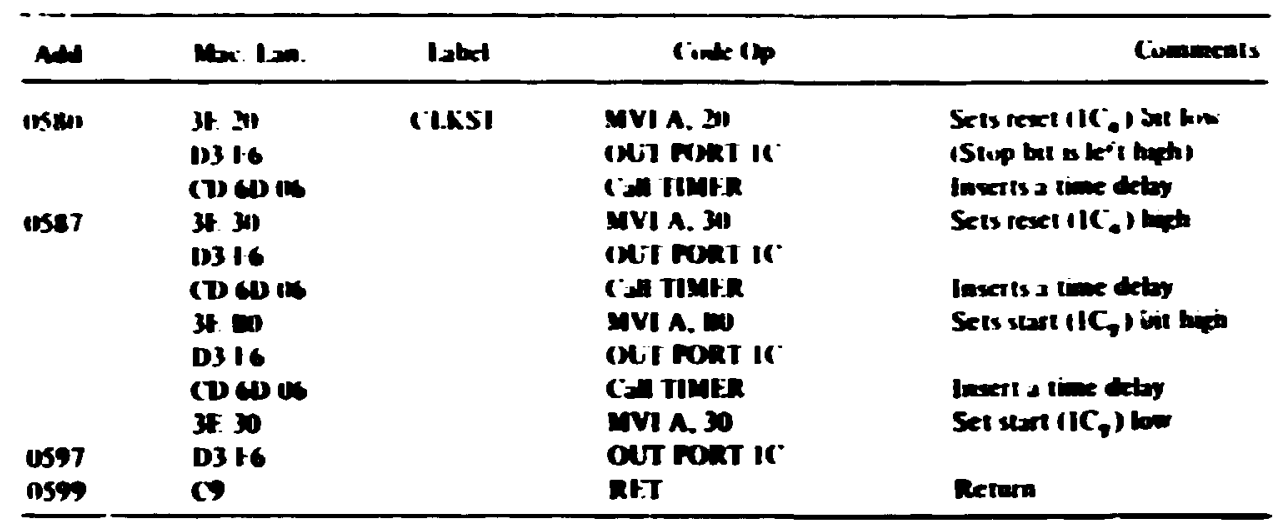

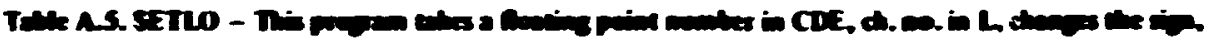

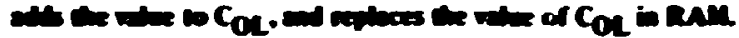

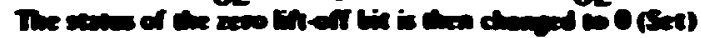

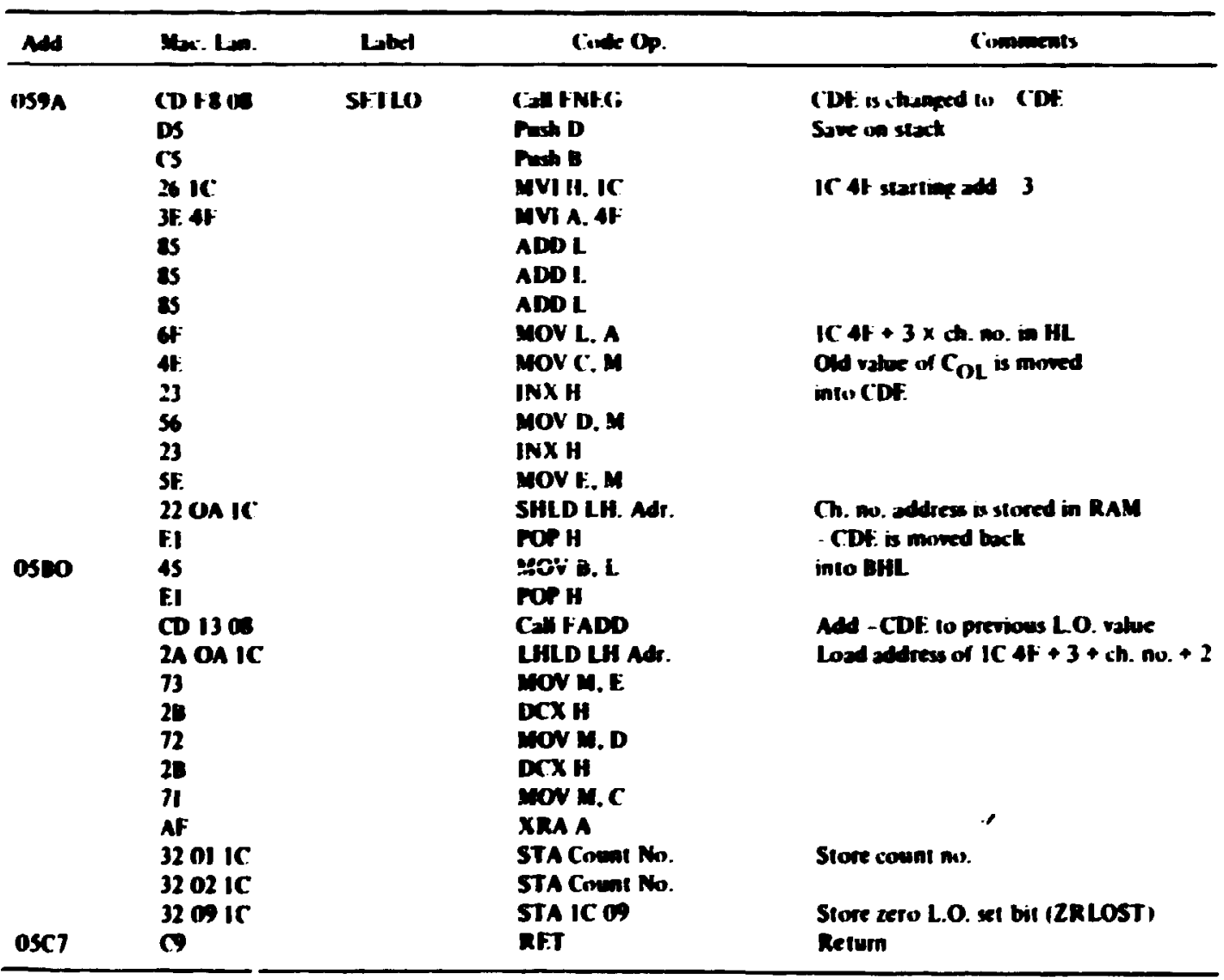




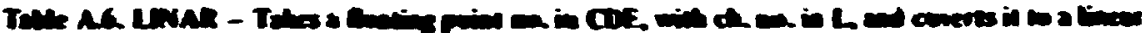

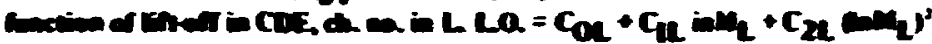

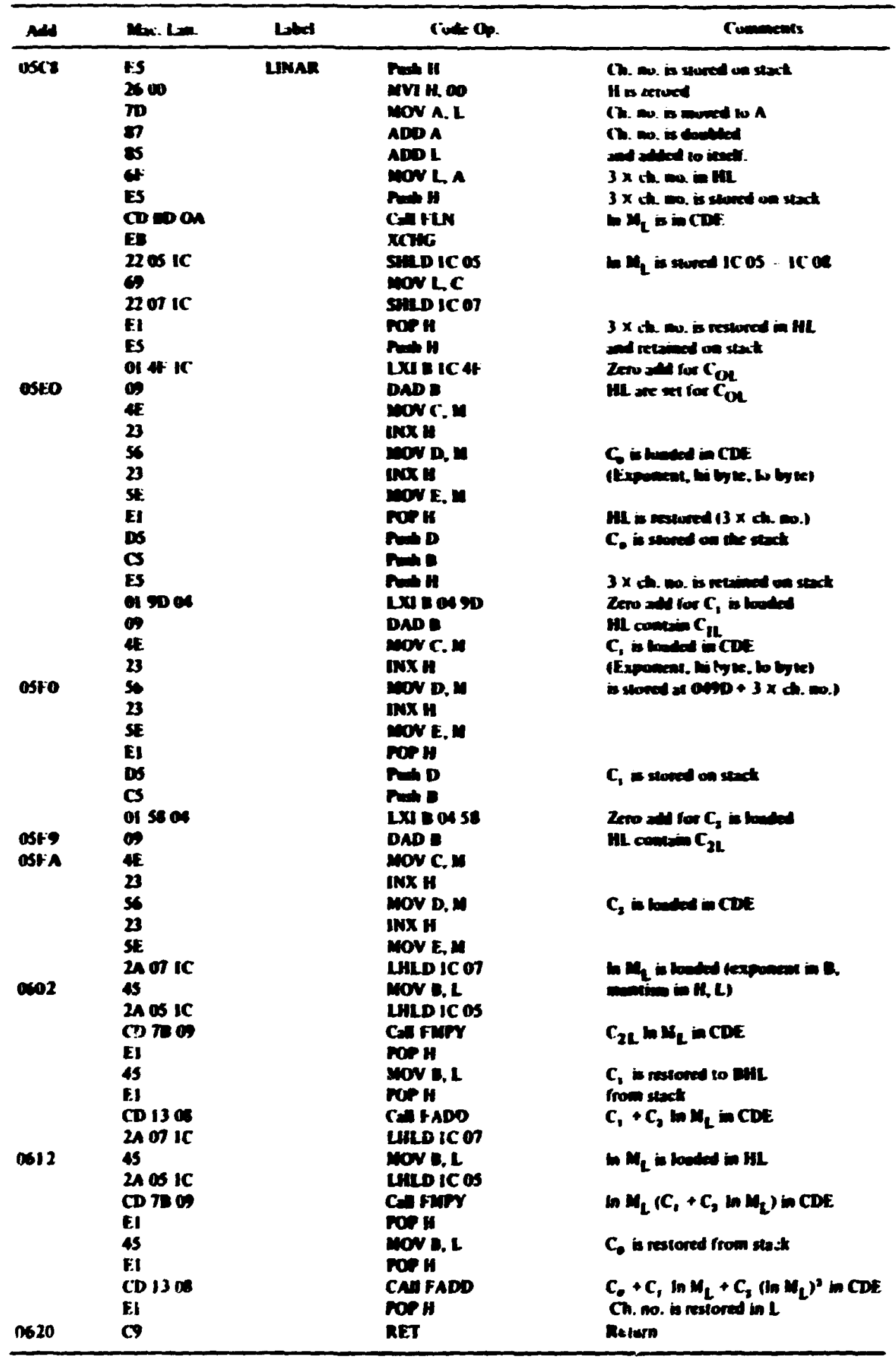


Tanc A. T. STIS

\begin{tabular}{|c|c|c|c|c|}
\hline wh & Me Is & Istel & I nde ip & ( onmen:V \\
\hline $14: 8$ & $\begin{array}{l}\text { (1) } 40 \text { is } \\
31 \text { i: } \\
11316 \\
1320 \text { in) }\end{array}$ & SINP & 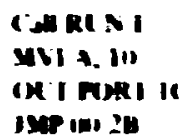 & 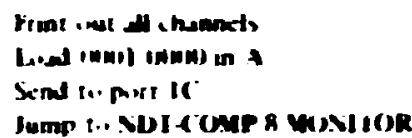 \\
\hline
\end{tabular}

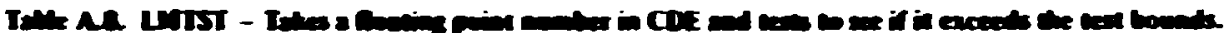

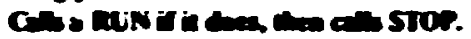

\begin{tabular}{|c|c|c|c|c|}
\hline Mes & Mar: Lm. & Lot & Cust $\mathbf{0}$ & Civmoneats \\
\hline \multirow[t]{13}{*}{ W2E } & is & IXISI & Purb & Surec Dot un stset \\
\hline & $2100 \mathrm{AO}$ & & IXI H. Anแ" & 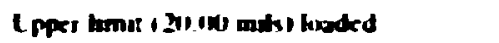 \\
\hline & 1045 & & 2010.45 & mז" внL. \\
\hline & $\begin{array}{l}101000 \\
79\end{array}$ & & $\begin{array}{l}\text { CHIST: } \\
\text { wNAC }\end{array}$ & 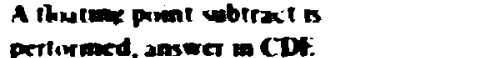 \\
\hline & $16 \mathrm{mo}$ & & AN & 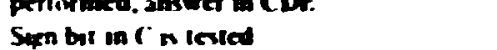 \\
\hline & $1421 \mathrm{cs}$ & & CN2 STIR & 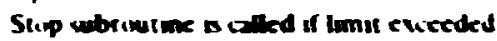 \\
\hline & b) & & $\min$ & LIturt! e restured to CDt. \\
\hline & $21 \boldsymbol{M}$ & & T) & 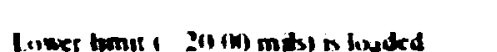 \\
\hline & ascs & & Mvi B.cs & 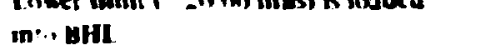 \\
\hline & $\operatorname{co~} 10 \mathrm{uss}$ & & rall ese: & A thutan punnt wbiract is pertintmed \\
\hline & & & $\operatorname{MoN}+\mathrm{C}$ & Sugn bit of answet wiesied. \\
\hline & 1600 & & ANU 8) & \\
\hline & CC 2106 & & izstor & STOP wbrinutine as idlked if ancmer is + \\
\hline w4e & $\mathbf{9}$ & & RE:T & Return \\
\hline
\end{tabular}

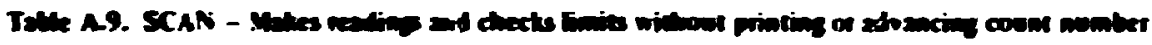

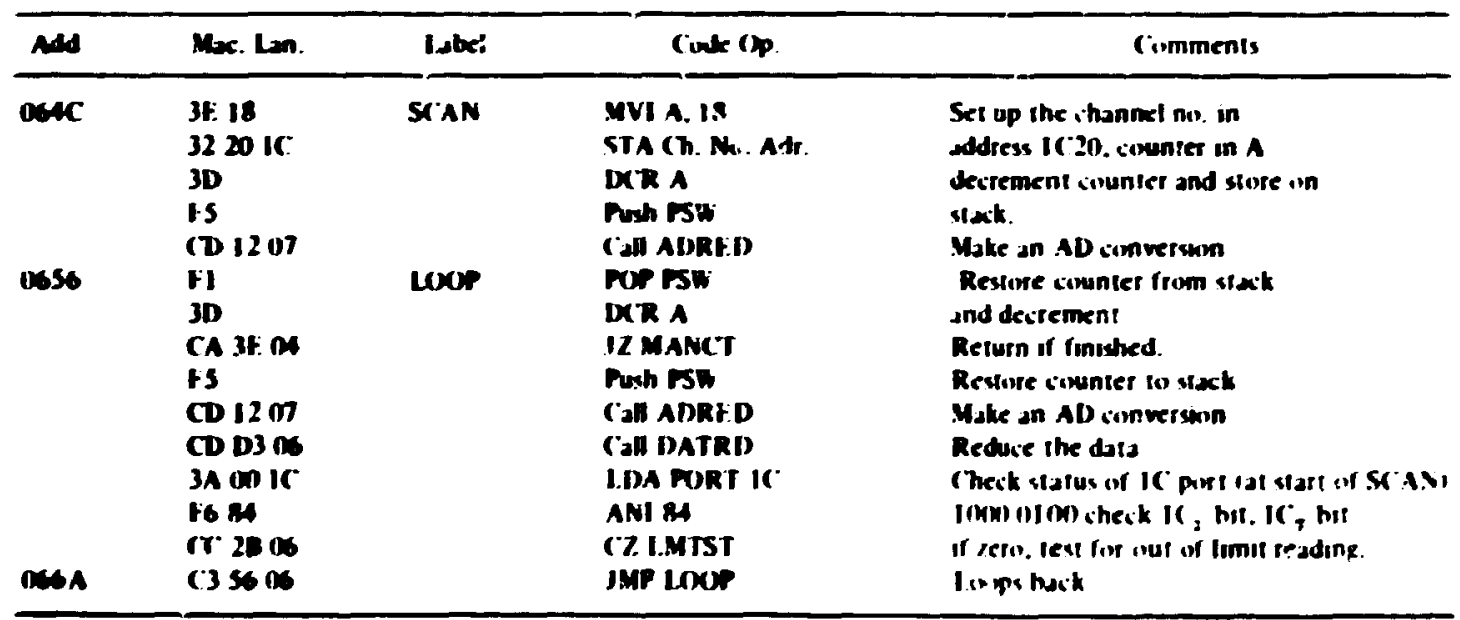




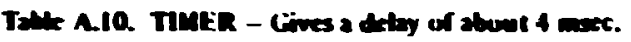

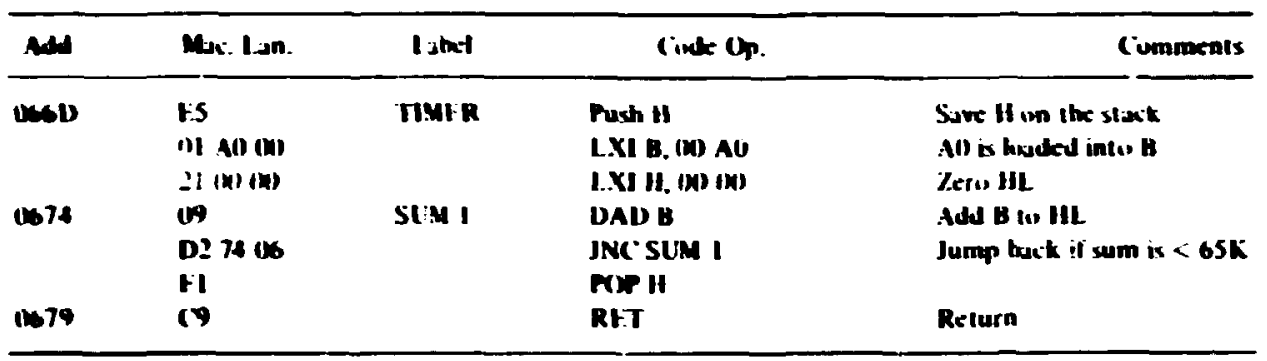

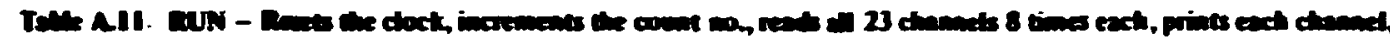

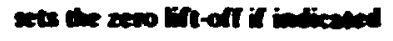

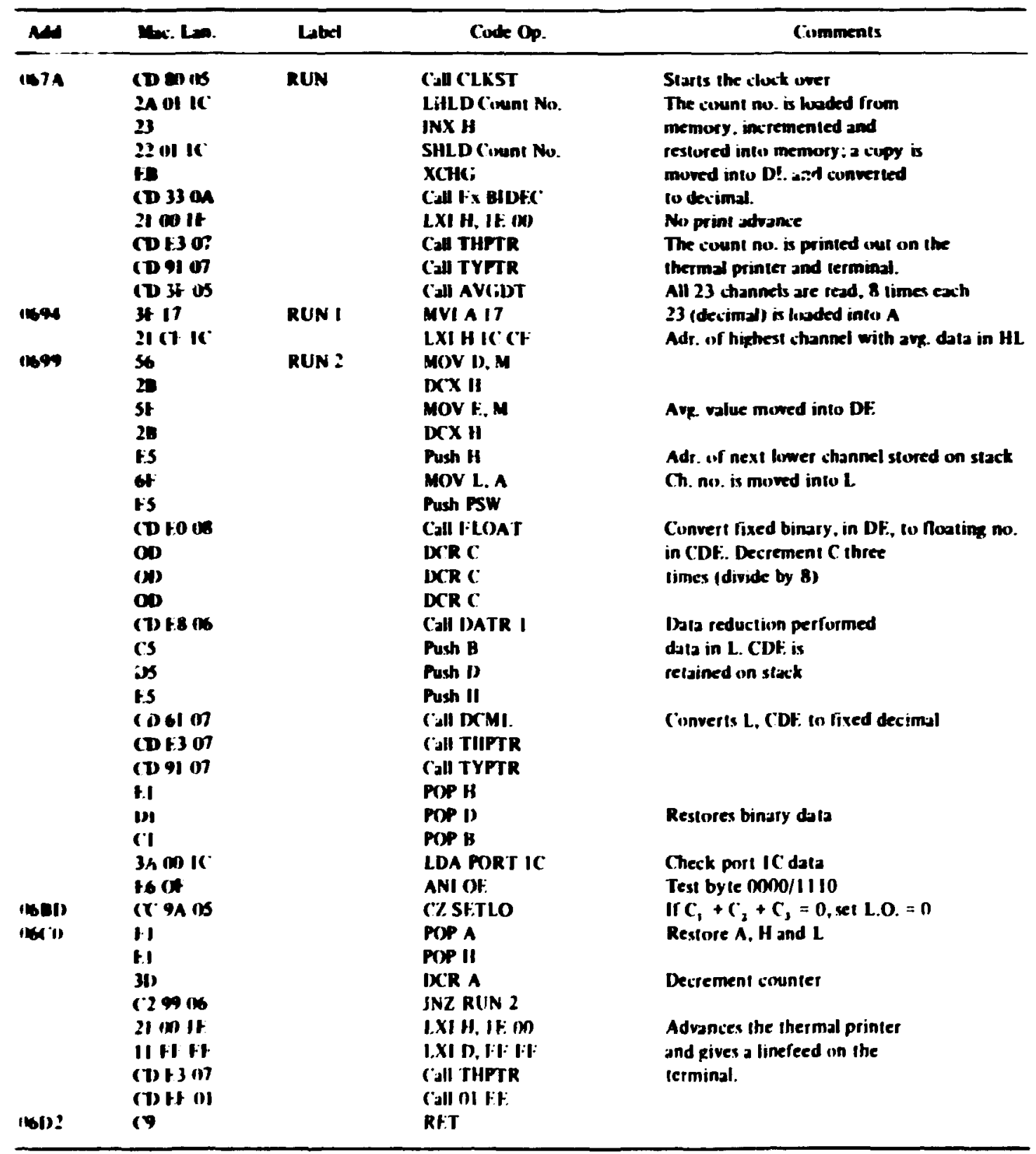




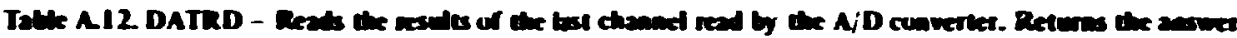

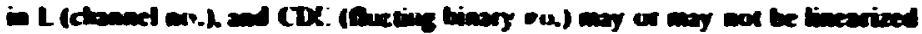

\begin{tabular}{|c|c|c|c|c|}
\hline Adw & Max: Ln. & Lubet & Cince Cp. & Cumbents \\
\hline (wo) & $\begin{array}{l}212110 \\
41 \\
\text { OD } \\
\text { C DD O6 } \\
\text { Or: } 17\end{array}$ & DATRD & $\begin{array}{l}\text { IXI H. (h. Nu. Adr. } \\
\text { MOVC. M } \\
\text { DCR C } \\
\text { JNZ CONT } \\
\text { MVI C. } 17\end{array}$ & 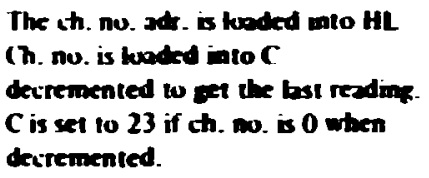 \\
\hline OSIY) & $\begin{array}{l}0600 \\
09 \\
09 \\
58 \\
23 \\
56\end{array}$ & cont & $\begin{array}{l}\text { MVI B. O0 } \\
\text { DAD } 9 \\
\text { DAD B } \\
\text { MOV H.M } \\
\text { INX H } \\
\text { MOV D.M }\end{array}$ & $\begin{array}{l}\text { B is zetoed } \\
\text { HL now contrins di. wo. adr. + next } \\
\text { ch. no. } \\
\text { The last value read is } \\
\text { moved into DS. }\end{array}$ \\
\hline & & & $\begin{array}{l}\text { MOV L.C } \\
\text { Can FLOT }\end{array}$ & $\begin{array}{l}\text { I. move contains the ch. ms. } \\
\text { bata is therted into C.Dt: }\end{array}$ \\
\hline Osti8 & $\begin{array}{l}3 A 00) \\
\text { Ho } 04 \\
\text { cc ce os }\end{array}$ & DATR I & $\begin{array}{l}\text { LDA MORT IC } \\
\text { ANI OA } \\
\text { CZ UAAR }\end{array}$ & 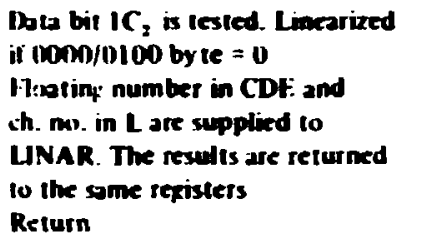 \\
\hline
\end{tabular}

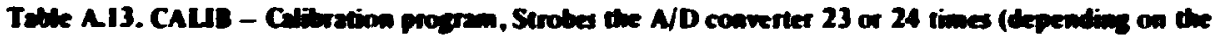

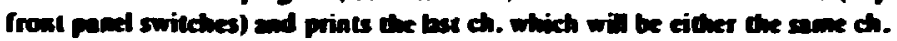

or anc reabet than the one read betore.

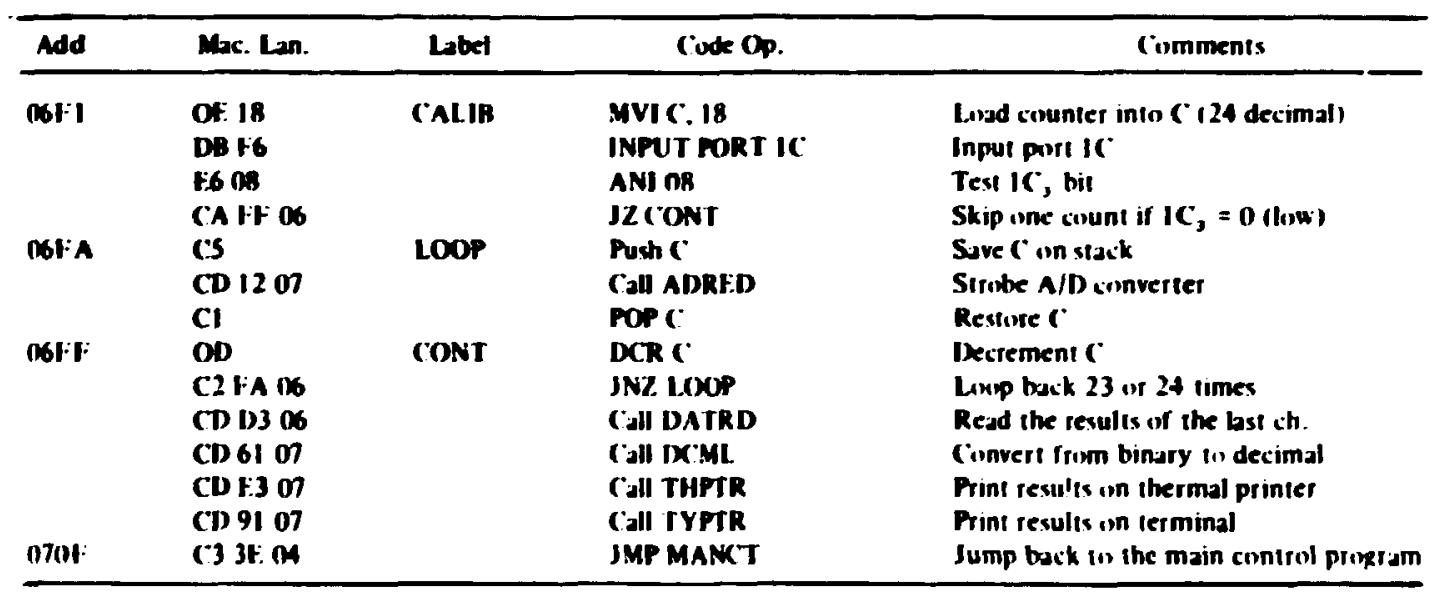




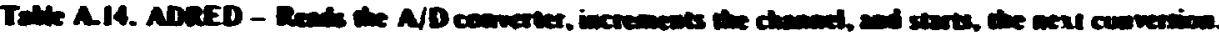

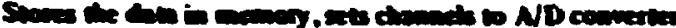

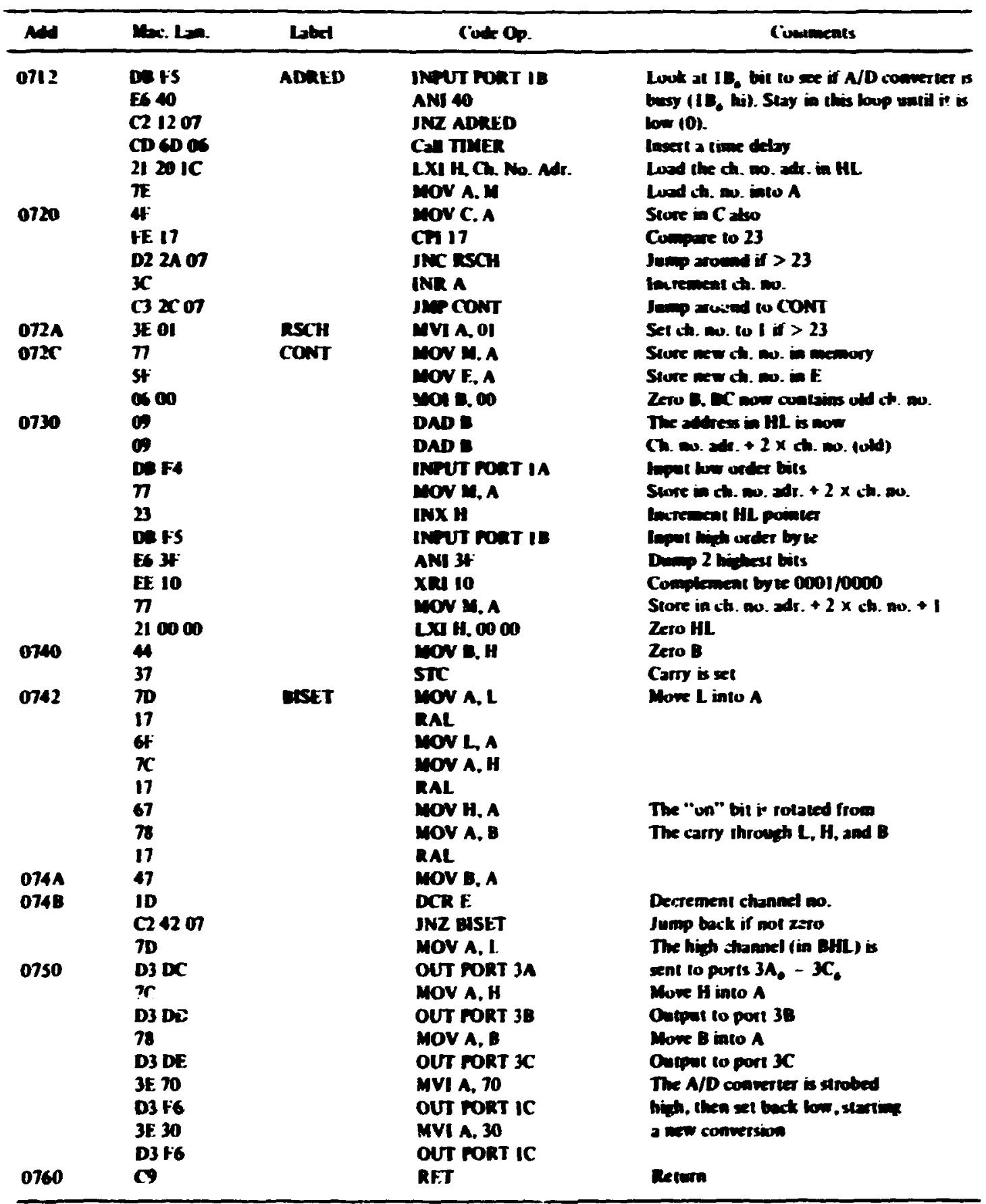




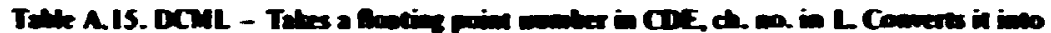

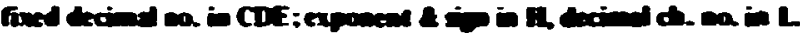

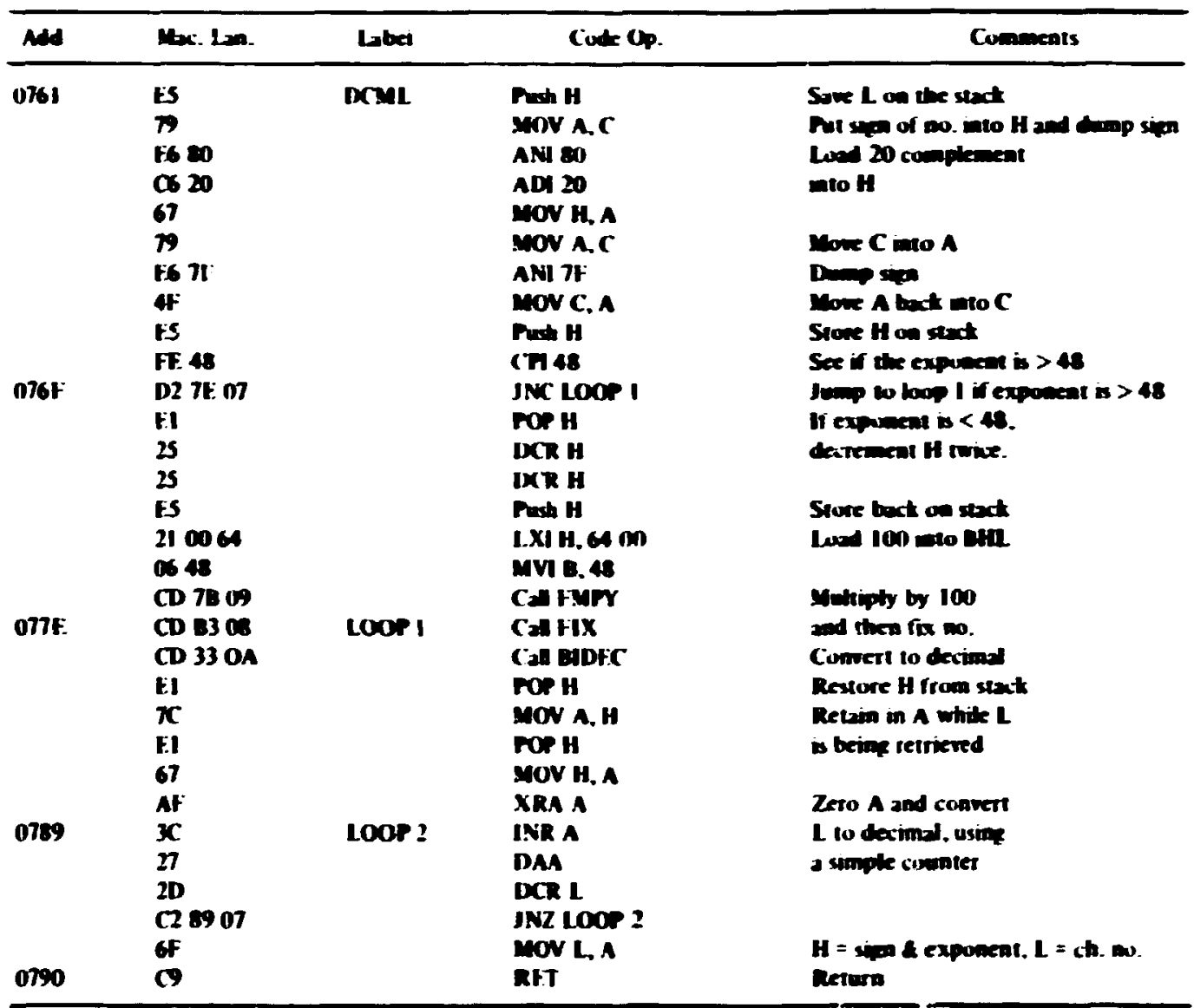




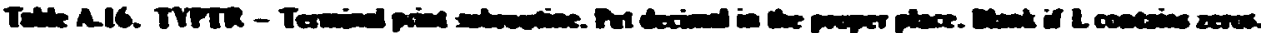

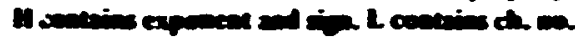

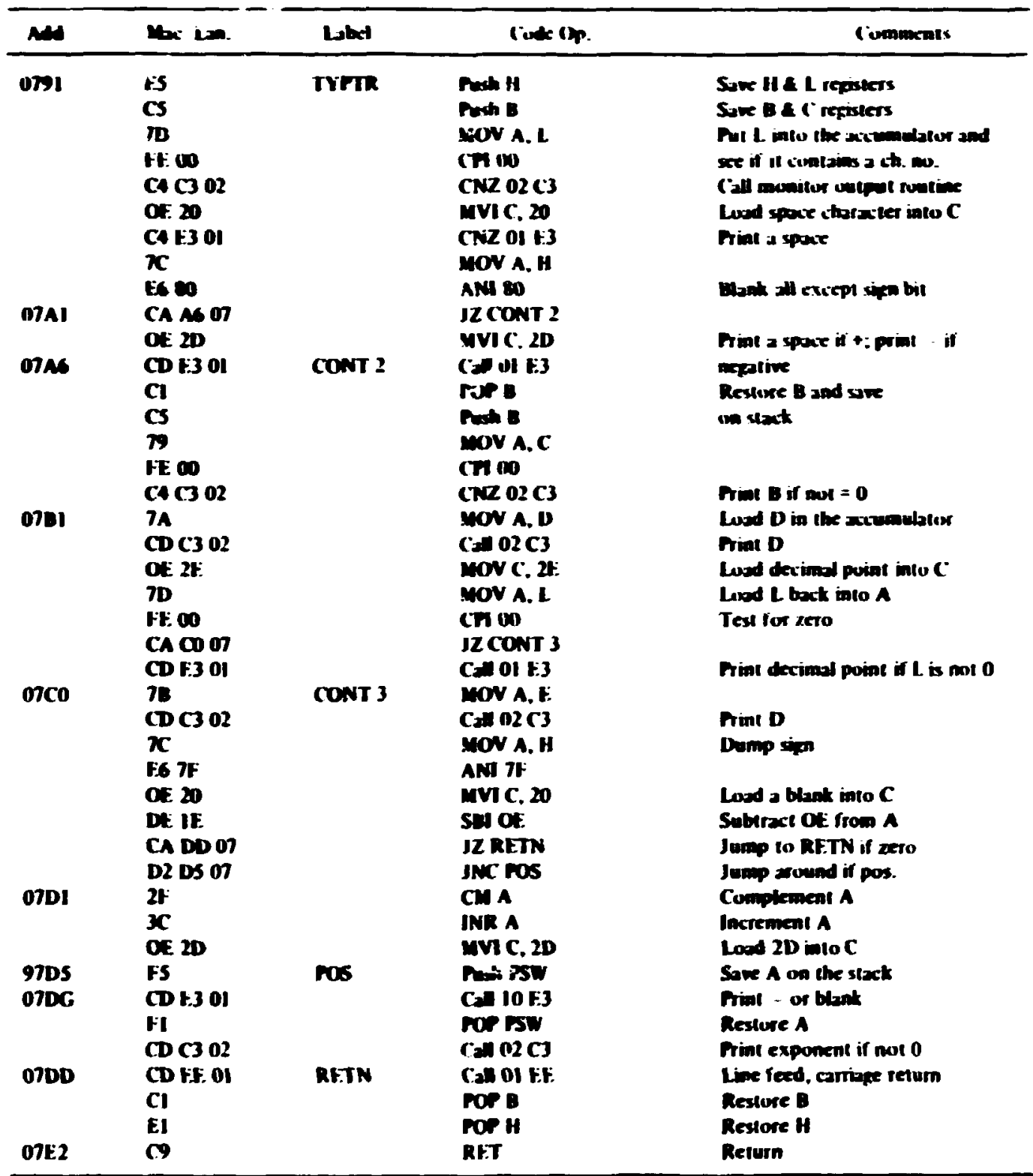




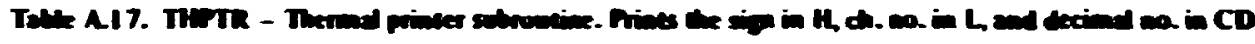

\begin{tabular}{|c|c|c|c|c|}
\hline add & Ybx: In. & Lubet & Cude op. & Comments \\
\hline ort: 3 & 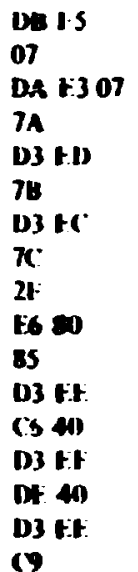 & THFTR & 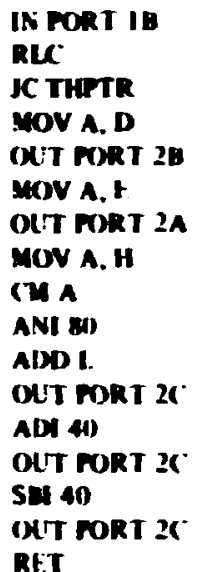 & 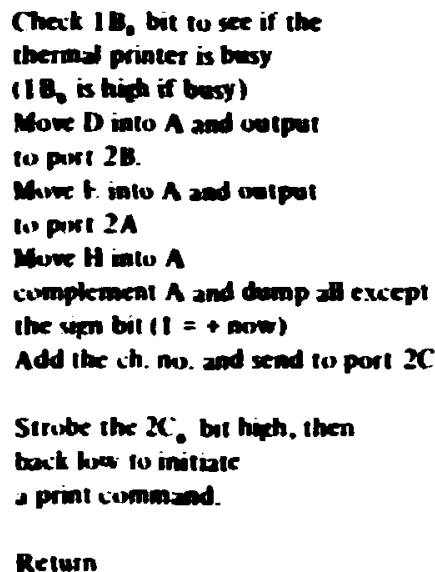 \\
\hline
\end{tabular}

